\title{
ESTABILIDADE OXIDATIVA DA CARNE DE FRANGOS ALIMENTADOS COM DIFERENTES FONTES LIPÍDICAS, ARMAZENADA SOB CONGELAMENTO
}

\section{LILIAN MARQUES PINO}

Dissertação apresentada à Escola Superior de Agricultura "Luiz de Queiroz", Universidade de São Paulo, para obtenção do título de Mestre em Ciências, Área de Concentração: Ciência e Tecnologia de Alimentos.

PIRACICABA

Estado de São Paulo - Brasil

Janeiro - 2005 


\section{ESTABILIDADE OXIDATIVA DA CARNE DE FRANGOS ALIMENTADOS COM DIFERENTES FONTES LIPÍDICAS, ARMAZENADA SOB CONGELAMENTO}

\section{LILIAN MARQUES PINO}

Engenheiro Agrônomo

Orientadora: Profa. Dra. MARISA A. B. REGITANO d'ARCE

Dissertação apresentada à Escola Superior de Agricultura "Luiz de Queiroz", Universidade de São Paulo, para obtenção do título de Mestre em Ciências, Área de Concentração: Ciência e Tecnologia de Alimentos.

PIRACICABA

Estado de São Paulo - Brasil

Janeiro - 2005 
Dados Internacionais de Catalogação na Publicação (CIP) DIVISÃO DE BIBLIOTECA E DOCUMENTAÇÃO - ESALQ/USP

\section{Pino, Lilian Marques}

Estabilidade oxidativa da carne de frangos alimentados com diferentes fontes lipídicas, armazenada sob congelamento / Lilian Marques Pino. - - Piracicaba, 2005.

$60 \mathrm{p}$.

Dissertação (Mestrado) - - Escola Superior de Agricultura Luiz de Queiroz, 2005.

Bibliografia.

1. Ácido graxo 2. Análise de alimento 3. Bioquímica de alimento 4. Carne de frango

5. Composição de alimento 6 . Conservação de alimento por congelamento 7 . Nutrição animal

8. Oxidação 9. Qualidade do alimento I. Título

CDD 664.93

"Permitida a cópia total ou parcial deste documento, desde que citada a fonte - O autor" 
Aos meus pais Antonio Francisco e Sônia, por sempre acreditarem em mim

A Maria José de Aguiar Pino (in memoriam) por me transmitir paz e serenidade Aos meu irmãos Júnior e Ana Paula DEDICO

Ao Luccas por todos os momentos OFEREÇO 


\section{AGRADECIMENTOS}

À Deus;

Aos meus pais, pelo amor, educação, estímulo e exemplos de vida;

Aos meus irmãos Júnior e Ana Paula, pelo carinho;

Ao Luccas G. Rodrigues Longo, pela compreensão, apoio, estímulo e dedicação constante em todos os momentos;

À minha orientadora, Profa. Dra. Marisa A. B. Regitano d'Arce responsável pela minha formação científica e exemplo de profissional, meu eterno agradecimento, pela paciência, estímulo, apoio, confiança e amizade durante todos estes anos;

À amiga Maria Fernanda de Almeida Prado, sempre disposta a ajudar, pelo auxilio técnico e pelos momentos de alegria em todo o decorrer deste trabalho;

Ao Prof. Dr. José Fernando M. Mentem pela doação dos animais;

À Dra. Aline Calil Racanicci pela amizade, sugestões e auxílio durante todo o trabalho;

À FAPESP, pela concessão da bolsa de mestrado;

Ao Prof. Severino Matias de Alencar e a técnica Ivani Moreno, pelo auxilio nas análises cromatográficas;

À amiga Denise de Oliveira Biato, pela ajuda e amizade em todos estes anos;

Às estagiárias Bruna Bonim e Mariana Marchesan, pelo auxílio na condução do experimento;

Aos amigos Daniela Cordeiro e Eduardo Salan, pelo auxílio na 
embalagem da matéria-prima;

Aos professores Drs. Marília Oetterer, Carmem Contreras Castillo e Eduardo Vicente, pelas sugestões e auxílio nas correções;

Aos amigos e companheiros de laboratório Aelson Brum, Selma Pacheco e Talita Benedetti, sempre dispostos a ajudar;

À bibliotecária Beatriz Helena Giongo, pela correção deste trabalho;

À Roberta Tereza Rizzo Benatto, pela amizade e pelo auxílio na formatação deste trabalho;

À Dra. Juliana Giannotti, pela paciência e auxílio na análise estatística;

Aos provadores do painel de análise sensorial;

À todos os funcionários do Departamento de Agroindústria, Alimentos e Nutrição, que direta ou indiretamente colaboraram para a realização desta pesquisa, agradeço. 


\section{SUMÁRIO}

Página

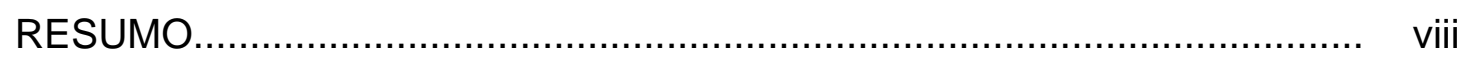

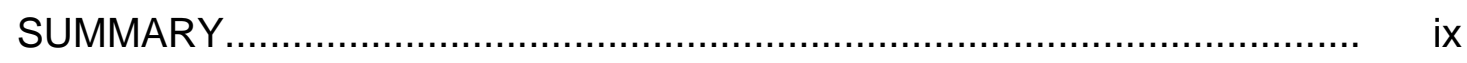

1 INTRODUÇÃO

2 REVISÃO DE LITERATURA............................................................... 2

2.1 Composição lipídica da carne..........................................................

2.2 Influência da alimentação animal nos lipídios da carne............................ 5

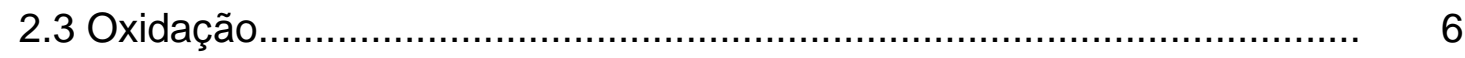

2.4 Alimentos Congelados............................................................... 13

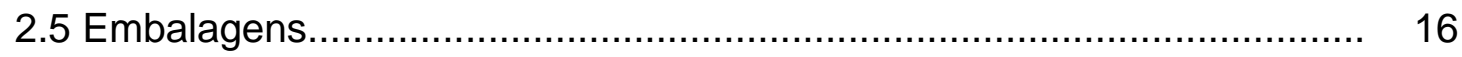

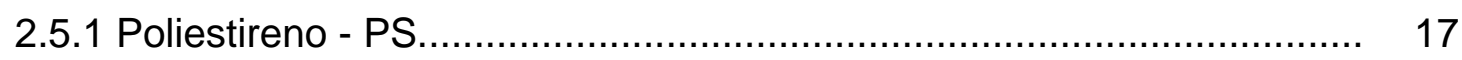

2.5.2 Policloreto de vinila - PVC........................................................... 17

2.6 Caracterização das fontes lipídicas....................................................... 17

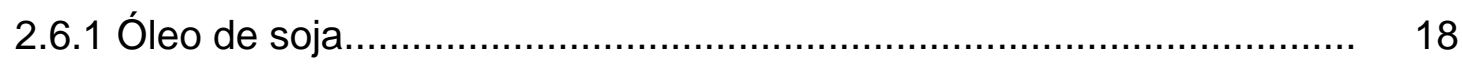

2.6.2 Óleo ácido de soja..................................................................... 20

2.6.3 Óleo de vísceras de aves............................................................... 20

3 MATERIAL E MÉTODOS................................................................... 22

3.1 Criação dos animais................................................................. 22

3.2 Abate e ensaio de armazenamento congelado........................................ 23

3.3 Caracterização química das fontes lipídicas.......................................... 23

3.4 Caracterização química, física e sensorial da carne de frango................ 28

3.5 Métodos........................................................................... 28

3.5.1 Composição centesimal................................................................ 28 


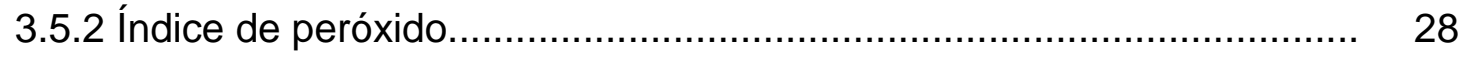

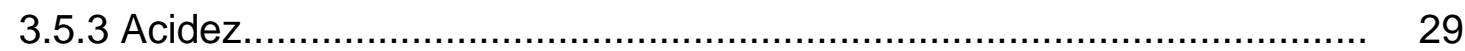

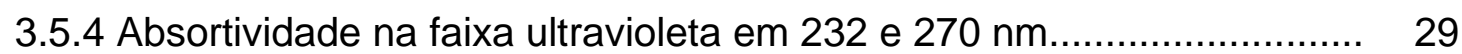

3.5.5 Perfil de ácidos graxos............................................................... 30

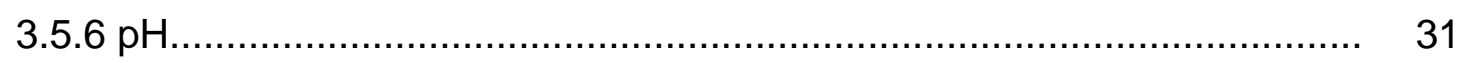

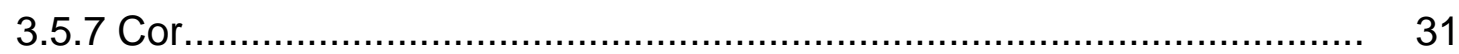

3.5.8 TBARS (Thiobarbituric acid reactive substances)............................. 31

3.5.9 Análise Sensorial..................................................................... 33

3.5.10 Análise Estatística...................................................................... 34

4 RESULTADOS E DISCUSSÃO............................................................. 35

4.1 Análises das fontes lipídicas da dieta................................................ 35

4.2 Composição centesimal.............................................................. 38

4.3 Perfil de ácidos graxos da carne de sobrecoxas................................... 39

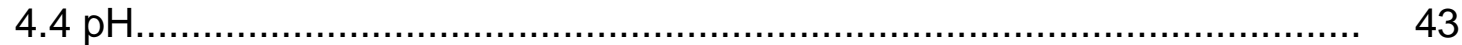

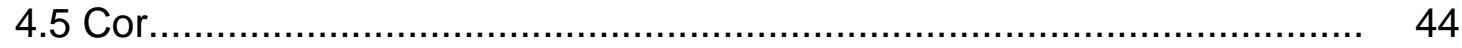

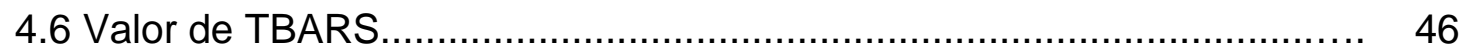

4.7 Análise Sensorial........................................................................ 48

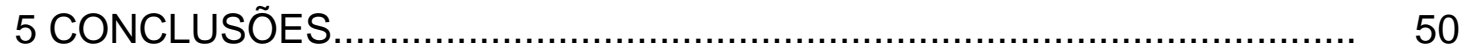

REFERÊNCIAS BIBLIOGRÁFICAS........................................................ 52 


\section{ESTABILIDADE OXIDATIVA DA CARNE DE FRANGOS ALIMENTADOS COM DIFERENTES FONTES LIPÍDICAS, ARMAZENADA SOB CONGELAMENTO}

Autora: LILIAN MARQUES PINO Orientadora: Profa. Dra. MARISA A. B. REGITANO d'ARCE

\section{RESUMO}

Este estudo teve como objetivo caracterizar química e fisicamente a carne de sobrecoxas de frangos alimentados com diferentes fontes lipídicas (óleo de soja - OS, óleo ácido de soja - AC e óleo de vísceras de frangos - FR) e a mistura destas (25\% óleo de soja + 75\% óleo ácido de soja - OS25AC75, $50 \%$ óleo de soja + 50\% óleo ácido de soja - OS50AC50, 50\% óleo de soja + $50 \%$ óleo de vísceras de frangos - OS50FR50) e estudar a estabilidade oxidativa das sobrecoxas, durante nove meses de armazenamento sob congelamento $\mathrm{a}^{-1} 8^{\circ} \mathrm{C}$. Foram determinadas a composição centesimal, o perfil de ácidos graxos, pH e cor para a caracterização e valor de TBARS para o acompanhamento da estabilidade oxidativa das sobrecoxas de frangos. A umidade e o teor de proteína bruta variaram de 68 a 70\% e 16,33 a 18,19\%, respectivamente, encontrando-se dentro da faixa de valores citados pela literatura. Os teores de óleo de 11,0 a $11,72 \%$ foram superiores aos encontrados na literatura, o que provavelmente se deve a diferenças de raça dos animais, idade de abate e tipo de alimentação. Ao longo do experimento os valores de $\mathrm{pH}$ variaram de 5,88 a 6,39 , sendo que apenas o tratamento 
OS25AC75 foi influenciado pelo tempo de armazenamento. A cor também se alterou em todos os tratamentos com o tempo. O perfil de ácidos graxos da fração lipídica da carne de sobrecoxa dos animais submetidos aos tratamentos estudados está de acordo com a literatura, sendo que a carne dos animais alimentados com a dieta adicionada de óleo ácido de soja apresentou uma quantidade de ácidos graxos insaturados inferior aos demais tratamentos. Os valores médios de TBARS variaram de 0,21 a $0,90 \mathrm{mg}$ de malonaldeído $/ \mathrm{kg}$, ao longo do experimento. A carne de frangos alimentados com OS50FR50 foi a que apresentou a menor estabilidade, ainda mais significativa no final do estudo, o que foi confirmado através da intensidade do odor de ranço, durante a análise sensorial. De forma geral, o armazenamento afetou a qualidade da fração lipídica da carne de sobrecoxas de frangos. 


\title{
OXIDATIVE STABILITY OF CHICKEN THIGH FROM BROILERS FED WITH DIFFERENT FAT SOURCES STORED UNDER FREEZING
}

\author{
Author: LILIAN MARQUES PINO \\ Adviser: Profa. Dra. MARISA A. B. REGITANO d'ARCE
}

\section{SUMMARY}

This work had the objective to characterize chemically and physically the meat of chicken thighs, fed with different lipid sources (soy oil, acid soy oil and chicken offal oil) and the mixture of these $(25 \%$ soy oil $+75 \%$ acid soy oil OS $25 A C 75,50 \%$ soy oil $+50 \%$ acid soy oil - OS50AC $50,50 \%$ soy oil $+50 \%$ chicken oil - OS50FR50) and to evaluate the oxidative stability of the meat, during nine months of frozen storage, under ${ }^{-} 18^{\circ} \mathrm{C}$. Bromatological and fatty acid composition, $\mathrm{pH}$ and color determinations were performed for the chemical and physical evaluation, as well TBARS value for the chicken thigh oxidative stability monitoring. The moisture and the crude protein values ranged from 68 to $70 \%$ and from 16.33 to $18.19 \%$ respectively, within the range of values found in the literature. The fats contents from 11.0 to $11.72 \%$ were higher than those found in the literature, which probably is justified by the differences in animal breed, age of slaughtering and type of feeding. Along the experiment, the values of $\mathrm{pH}$ varied from 5.88 to $6.39 \%$, however only OS25AC75 was influenced by the time. The color was affected by storage in all treatments. The fatty acid content of lipid 
fraction of the thigh chicken meat was in accordance whith the literature, the chicken meat of animals fed with diet added of acid soy oil presented a least unsatturated fat acid of the all treatments. The average TBARS values varied from 0.21 to $0.90 \mathrm{mg}$ malonaldehyde/kg. The thigh meat from broilers fed OS50FR50 was the one that presented the least stability, even more significant at the end of the experiment wich was confirmed with intensity rancidity flavor detected by the sensory analysis. In general the time of storage affected the oxidative quality of the lipid fraction. 


\section{INTRODUÇÃO}

Os óleos e gorduras são muito utilizados na indústria avícola como fonte concentrada de energia nas rações de frangos de corte. Dentre as fontes utilizadas, o óleo de soja é o mais usado, no entanto o óleo ácido de soja, sebo bovino, óleo de vísceras de aves e a misturas destas, são boas alternativas, principalmente quando o preço do óleo de soja está elevado, para a obtenção de menores custos de produção, sem prejudicar o desempenho e a qualidade da carcaça das aves.

No entanto, o fornecimento de dietas com diferentes formulações provoca modificações na composição em ácidos graxos da carne. O tipo de gordura da dieta constitui a maior fonte de variação da composição dos ácidos graxos da carne, principalmente nos animais monogástricos.

Sabe-se que nos alimentos os lipídios afetam as propriedades de textura, suculência, sabor, aroma e cor, sendo um dos responsáveis pela aceitação da carne pelo consumidor. Depreende-se daí a importância de estudos de caracterização da carne de frangos alimentados com rações com diferentes fontes de energia bem como da sua qualidade de conservação durante a comercialização.

Este trabalho teve como objetivo caracterizar química e fisicamente a carne de sobrecoxas de frangos alimentados com dietas formuladas com diferentes fontes de energia, como óleo de soja, óleo de vísceras de frango, óleo ácido de soja e suas misturas, bem como estudar a estabilidade oxidativa da carne durante 9 meses de armazenamento sob congelamento, prazo permitido pela legislação. 


\section{REVISÃO DE LITERATURA}

Com a finalidade de reduzir gastos na avicultura industrial, principalmente o das rações, que participam com aproximadamente $70 \%$ do custo de produção final das aves, cujo item mais oneroso é a energia, têm-se utilizado misturas de óleos e gorduras das mais diversas origens.

A gordura é normalmente empregada como fonte de energia concentrada nas rações de frangos de corte. As gorduras comumente utilizadas são o óleo de soja, sebo bovino, óleo ácido de soja, banha de suínos, óleo de vísceras de aves (Gaiotto, 2004). O uso de quantidades expressivas destes ingredientes tem permitido a formulação de dietas de alta energia para frangos de corte, tornando-se o principal responsável pelos aumentos de produtividade e desempenho verificados nos últimos anos (Adams, 1999).

A composição e a quantidade de gordura usada em rações para aves pode variar grandemente de acordo com a sua origem, preço e formulação da dieta. As características principais das gorduras presentes na dieta estão relacionadas aos ácidos graxos que as compõem. Estes ácidos graxos podem diferir em função do seu estado, se em forma livre ou esterificados, saturados ou insaturados e se adicionados às rações diretamente na forma de gordura ou como parte integrante de outros ingredientes usados nas rações. A grande vantagem do uso de gordura na alimentação animal está relacionada à sua facilidade e rapidez de deposição nos tecidos de animais em crescimento, sendo este aspecto mais importante dentro da avicultura comercial do que seu uso como combustível para geração de energia. O tipo de gordura afeta a eficiência alimentar devido a algumas peculiaridades durante a sua digestão- 
absorção outros processos metabólicos (Gaiotto, 2004).

A digestão lipídica, que garante o aproveitamento das gorduras da dieta, ocorre especificamente no duodeno das aves, e é realizada principalmente pela lipase pancreática e sais biliares. Os sais biliares promovem a emulsificação das gorduras para posterior ação da lipase pancreática e colipase. Estas liberam os ácidos graxos esterificados aos carbonos 1 e 3 da molécula de glicerol, com a conseqüente produção de 2-monoglicerídeos e ácidos graxos livres. Tanto os sais biliares, quanto os 2-monoglicerídeos são grandes agentes emulsificantes, capazes de formar espontaneamente, junto com os ácidos graxos livres, as micelas de gordura que migram para as vilosidades do intestino, onde são absorvidos. Estes são ressintetizados na mucosa e combinam com transportadores, que os levam diretamente para o fígado através da corrente sanguínea (Scott et al., 1982; Maynard, 1984; Krogdahl, 1985).

\subsection{Composição lipídica da carne}

Os lipídios tem um papel determinante na aceitação da carne, já que a sua concentração e a composição influenciam fortemente as propriedades organolépticas (textura, sabor, aroma e cor).

O maior teor de lipídeos da carne está presente no músculo, sendo bastante variável, de 1,5 a 13\%, e consistindo de lipídeos de depósito e estruturais (Cobos et al., 1994).

Os lipídeos de depósito são fonte de energia celular. São constituídos por ésteres de glicerol com ácidos graxos, predominando os triglicerídeos, podendo também conter pequenas quantidades de monoglicerídeos, diglicerídeos e ácidos graxos livres. Alguns lipídeos neutros estão acumulados em quantidades microscopicas no interior de células musculares, porém a maioria se localiza nos tecidos conectivos (Cobos et al. 1994). São os lipídeos intramusculares (Allen e Foegeding, 1981; German, 1990), que variam de acordo com a espécie, raça, tipo de músculo, tecido, dieta e influências 
ambientais (German, 1990).

Em contraste com os de reserva, os lipídeos das membranas celulares apresentam uma composição similar em todas as espécies animais, mesmo sob diferentes condições ambientais e de dieta (German, 1990). Os lipídeos polares contêm um teor maior de ácidos graxos polinsaturados que os triglicerídeos (Sinclair et al., 1982; Cambero et al., 1991a e b). Cobos et al. (1994) observaram que os ácidos graxos dos fosfolipídeos do músculo esquelético são muito similares entre as espécies, tanto em ruminantes como em monogástricos. No entanto, constatou-se que é possível encontrar uma ampla variação na composição dos fosfolipídeos celulares relacionados com o crescimento e a viabilidade das células (Cobos et al., 1994). Nas membranas celulares ainda há outros tipos de lipídeos, como os estruturais, tais como fosfolípideos e o colesterol, essenciais para a função celular (Allen e Foegeding, 1981).

Os ácidos graxos diferem quanto ao comprimento da cadeia hidrocarbonada, número e tipo de ligações que unem os átomos de carbono, tornando-os de cadeia curta, média e longa, saturados e insaturados. A grande maioria dos ácidos graxos dos lipídeos animais tem número par de átomos de carbono. Os principais ácidos graxos saturados da carne são palmítico (C16:0), esteárico (C18:0) e mirístico (C14:0). O ácido oléico (C18:1) é o monoinsaturado mais abundante, seguido do palmitoléico (C16:1). Os ácidos linoléico (C18:2), linolênico (C18:3) e araquidônico (C20:4) são os principais ácidos graxos poliinsaturados. Os ácidos graxos saturados e monoinsaturados são os constituintes mais importantes dos triglicerídeos da fração lípidica da carne (Rhee, 1992).

O perfil de ácidos graxos nos lipídeos de depósito pode variar em função da espécie do animal, raça, sexo, idade e alimentação. Os ácidos graxos dos tecidos de animais ruminantes apresentam uma tendência de serem mais saturados devido à ação dos microorganismos presentes no rúmen, que hidrogenam os ácidos graxos insaturados das dietas (Cobos, 1994). A carne de 
frango apresenta mais ácidos graxos polinsaturados do que as carnes vermelhas (Rhee, 1992).

\subsection{Influência da alimentação animal nos lipídeos da carne}

O tipo de gordura da dieta constitui a maior fonte de variação na composição dos ácidos graxos dos lipídeos de depósito, principalmente em animais monogástricos. Asghar et al. (1990) verificaram que dietas de frangos adicionadas de diferentes tipos de gorduras como sebo, óleo de soja, oliva, linhaça, coco e manteiga de cacau afetaram a composição dos ácidos graxos na carne dos animais.

A alimentação com dietas adicionadas de gorduras com um alto teor de ácido linoléico, como óleo de soja, provocou o aumento da deposição deste ácido e do ácido araquidônico na gordura de suínos (Morgan et al., 1992), coelhos (Cobos et al., 1994) e frangos (Asghar et al., 1990). O incremento em ácido araquidônico na carne se deve à síntese deste ácido a partir do ácido linoléico.

Asghar et al. (1990) verificaram um acúmulo de ácido linolênico bem como no teor total de ácidos graxos poliinsaturados da família $n-3$, como o ácido eicosapentaenóico (C20:5) e docosahexaenóico (C22:6), e uma diminuição das quantidades de ácido araquidônico e demais PUFA da família $n$ 6, como o docosapentaenóico (C22:5), nos fosfolipídios da gordura de frangos, alimentados com dieta adicionada de óleo de linhaça (alta concentração de ácido linolênico).

Morgan et al. (1992) observaram que a adição na dieta de gorduras com ácidos graxos como o eicosapentaenóico (C20:5, n-3) e docosahexaenóico (C22:6, n-3) provocou a elevação significativa dos seus níveis nos lipídeos da carne e concomitante redução dos teores do ácido araquidônico em suínos.

Os principais efeitos tecnológicos adversos associados à modificação da composição quantitativa de ácidos graxos dos lipídeos da carne são os originados da qualidade organoléptica, como aroma e sabor anômalos, devidos 
a processos de oxidação desses ácidos polinsaturados, além da redução da firmeza da carne, baixa suculência e pouca aceitabilidade.

\subsection{Oxidação}

A oxidação lipídica é o principal processo pelo qual ocorre perda de qualidade da carne e seus produtos, depois da deterioração microbiana (Gray et al., 1996). Além da alteração de odor e gosto a oxidação lipídica está relacionada também com a oxidação dos pigmentos da carne, provocando perda de cor.

O processo de oxidação se inicia na ligação carbono-hidrogênio adjacente à dupla ligação da cadeia de carbono e pode ser catalisado por um grande número de fatores, especialmente ambientais (umidade, temperatura, luz e oxigênio), presença de metais (cobre, ferro e manganês), de enzimas e pigmentos (Adams, 1999). O processo autoxidativo pode ser explicado em três fases: início, propagação e término segundo modelo proposto por Farmer (1942):

- Iniciação:

$$
\mathrm{R}-\mathrm{H} \rightarrow \mathrm{R} \bullet+\mathrm{H} \bullet
$$

- Propagação:

$$
\begin{aligned}
& \mathrm{R} \bullet+\mathrm{O}_{2} \rightarrow \mathrm{R}-\mathrm{O}-\mathrm{O} \bullet \\
& \mathrm{RO}-\mathrm{O} \bullet+\mathrm{RH} \rightarrow \mathrm{R}-\mathrm{O}-\mathrm{OH}+\mathrm{R} \bullet
\end{aligned}
$$

- Término:

$$
\begin{aligned}
& \mathrm{R} \bullet+\mathrm{R} \bullet \rightarrow \mathrm{R}-\mathrm{R} \\
& \mathrm{R}-\mathrm{O}-\mathrm{O} \bullet+\mathrm{R} \bullet \rightarrow \mathrm{R}-\mathrm{O}-\mathrm{O}-\mathrm{R} \\
& \mathrm{R}-\mathrm{O}-\mathrm{O} \bullet+\mathrm{R}-\mathrm{O}-\mathrm{O} \bullet \rightarrow \mathrm{R}-\mathrm{O}-\mathrm{O}-\mathrm{R}+\mathrm{O}_{2}
\end{aligned}
$$


em que: $\mathrm{RH}$ - Ácido graxo insaturado

R• - Radical livre

ROO• - Radical peróxido

$\mathrm{ROOH}$ - Hidroperóxido

Nas fases de início e propagação, a presença de radicais livres, que são moléculas extremamente reativas, é decisiva (Adams, 1999). Essas formas reativas são normalmente produzidas durante o metabolismo do oxigênio nos tecidos e são chamadas de espécies reativas de oxigênio (ROS - Reactive Oxygen Species). Estes compostos dividem-se em radicais $\left(\mathrm{O}_{2}{ }^{-} \mathrm{e} \mathrm{HO} \bullet\right)$ ou não radicais $\left(\mathrm{H}_{2} \mathrm{O}_{2}\right)$. Alguns deles são produzidos durante o metabolismo aeróbio das células vivas, como o radical superóxido $\left(\mathrm{O}_{2}{ }^{-}\right)$, que é formado pela adição de um elétron extra ao oxigênio molecular $\left(\mathrm{O}_{2}\right)$, durante o processo de redução do oxigênio na cadeia respiratória mitocondrial. Da mesma forma, os macrófagos, quando estimulados, produzem $\mathrm{O}_{2}^{-}$e $\mathrm{H}_{2} \mathrm{O}_{2}$ durante o processo normal de fagocitose (Combs, 1998).

Mesmo apresentando pouca reatividade química, os compostos $\mathrm{O}_{2}{ }^{-} \mathrm{e}$ $\mathrm{H}_{2} \mathrm{O}_{2}$, quando expostos a determinados íons metálicos $\left(\mathrm{Fe}^{2+} \mathrm{e} \mathrm{Cu}^{2+}\right)$, geram um radical livre altamente reativo, o radical hidroxila ( $\mathrm{HO} \bullet)$.

Os metais bivalentes podem também catalisar a reação de decomposição do $\mathrm{H}_{2} \mathrm{O}_{2}$ ou do hidroperóxido $(\mathrm{ROOH})$ já produzido pela oxidação lipídica, formando os radicais $\mathrm{HO} \bullet$ ou $\mathrm{RO} \bullet$, respectivamente.

O radical hidroxila $(\mathrm{HO} \bullet)$ é provavelmente o radical livre mais importante para a iniciação do processo de oxidação nos tecidos animais, uma vez que ele pode rapidamente remover um átomo de hidrogênio do ácido graxo insaturado (Adams, 1999). Os principais alvos do radical hidroxila (HO•) são os lipídeos, especialmente os ácidos graxos insaturados da membrana celular, as proteínas e o DNA (Combs, 1998).

Os ácidos graxos insaturados da membrana celular são muito suscetíveis 
aos radicais livres $(\mathrm{HO} \bullet$ ou $\mathrm{RO} \bullet)$ devido a sua estrutura química, que permite a retirada de um átomo de hidrogênio de um dos grupos $-\mathrm{CH}_{2^{-}}$da cadeia

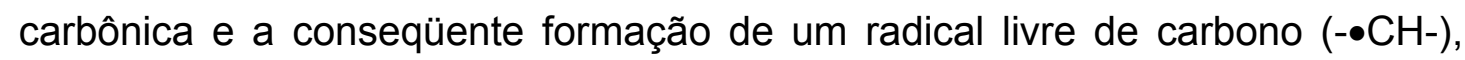
iniciando, assim, o processo de peroxidação lipídica. Estes radicais de carbono, que são instáveis e suscetíveis ao oxigênio molecular $\left(\mathrm{O}_{2}\right)$, se reestruturam rapidamente na forma de dienos conjugados, dando origem ao radical peroxila (ROO•). Segundo o modelo proposto por Farmer (1942), este radical tem a capacidade de retirar um átomo de hidrogênio de outro ácido graxo insaturado intacto, propagando a reação em cadeia até que todo ácido graxo insaturado da membrana seja completamente oxidado a hidroperóxido ( $\mathrm{ROOH})$.

Os hidroperóxidos são degradados na presença de metais de dupla valência, como $\mathrm{Cu}^{2+}$ e $\mathrm{Fe}^{2+}$ em estado livre (íons) ou ligados a proteínas (hemoglobinas), liberando radicais que dão seqüência à cadeia de reações de oxidação e outros produtos de clivagem como malonaldeídos e alcanos. Acredita-se que esta degradação oxidativa dos ácidos graxos insaturados da membrana fosfolipídica leva a mudanças físico-químicas que resultam em disfunções da membrana celular (Combs, 1998).

Apesar da intensa produção de radicais livres nos tecidos durante os processos metabólicos naturais, grandes quantidades destes compostos podem ter origem exógena e ser provenientes, por exemplo, da poluição, do consumo de alimentos oxidados, da fumaça dos cigarros, da radiação solar, dentre outros.

Logo após a morte do animal, inicia-se o processo de deterioração, que aumenta de intensidade até que a carne se torne inaceitável ao consumo. Durante o processo de conversão de músculo em carne ocorre uma série de mudanças bioquímicas que acompanham o metabolismo pós-abate e pós-morte e promovem condições para que o processo de oxidação se instale. Estas mudanças favorecem o desenvolvimento da oxidação da fração fosfolipídica altamente insaturada nas membranas subcelulares, uma vez que é improvável que os mecanismos de defesa das células do animal vivo ainda funcionem 
perfeitamente após o abate (Gray et al., 1996; Morrissey et al., 1998).

Os hidroperóxidos formados durante o processo de oxidação lipídica são essencialmente inodoros, contudo, eles se decompõem em uma grande variedade de compostos secundários voláteis e não-voláteis. Dentre estes, os aldeídos são os que mais contribuem para perda do aroma natural das carnes devido a sua alta velocidade de formação durante o processo de oxidação lipídica. De uma maneira geral, o odor desenvolvido nas carnes armazenadas sob refrigeração pode ser atribuído mais ao mascaramento do seu aroma natural resultante do aumento do conteúdo de odores desagradáveis no material armazenado, do que pela degradação do aroma original (Gray et al., 1996).

A oxidação lipídica em carnes pode ser acompanhada através do Valor de TBARS segundo Tarladigs et al. (1960), visto que produtos primários de oxidação lipídica constituem-se principalmente de hidroperóxidos, os quais são rapidamente decompostos em várias substâncias reativas ao ácido 2tiobarbitúrico (TBA), particularmente carbonilas, sendo o malonaldeído o elemento mais importante. O produto da reação destas substâncias com o TBA é colorido e absorve fortemente em 532nm. Racanicci (2004), utilizando essa metodologia, verificou que ao final de 12 dias de armazenamento refrigerado o valor de TBARS de sobrecoxas de animais alimentados com dietas formuladas com adição de óleo oxidado de vísceras de aves foi significativamente superior ao da carne dos animais alimentados com dieta formulada com óleo fresco, ao final de 12 dias de armazenamento. O mesmo também foi verificado para carne armazenada sob congelamento.

A oxidação também pode ser função da atividade de água do produto, propriedade de um alimento que pode ser definida como a água disponível para o crescimento microbiano ou demais reações de natureza química, física ou enzimática. Para os alimentos, em geral, com valores menores que 0,6 de atividade de água, a intensidade de deterioração é mais baixa, sendo cada vez menor à medida que este valor diminui (Figura 1). No entanto, a 
susceptibilidade de carnes congeladas à oxidação pode ser função da atividade de água (Aa). Enquanto que a carne fresca possui uma Aa de 0,99, durante o congelamento, os músculos mantidos sob temperaturas de ${ }^{-} 18^{\circ} \mathrm{C}$, ela pode ser reduzida a valores de até 0,6 . Como se pode visualizar através da Figura 1 , a atividade de água na faixa de 0,8 a 0,6 favorece o aumento das reações de oxidação lipídica (Van Laack, 1994).

Os alimentos perecíveis são os que oferecem maior disponibilidade de água para o crescimento microbiano. A redução da atividade de água é, portanto, fator preponderante na preservação de alimentos (Figura 1). Em geral, afirma-se que ao se reduzir a atividade de água de 0,85 para 0,65, a vida útil aumenta de uma semana para dois anos, desde que o produto seja devidamente embalado, de modo a manter a atividade de água constante ao longo da armazenagem (Labuza, 1982).

A atividade de água pode influenciar as reações químicas de diferentes maneiras. Pode também alterar a mobilidade dos reagentes e formar pontes de hidrogênio ou complexos com os reagentes. Dessa forma, um aspecto prático muito importante relacionado à atividade de água é controlar as reações químicas e enzimáticas indesejáveis, que reduzem a vida útil dos alimentos. $A$ velocidade das alterações nas propriedades dos alimentos pode ser minimizada ou acelerada dependendo do valor da atividade de água (Sarantópoulos, 2001).

A umidade relativa do ambiente é importante e pode influenciar a atividade de água de um alimento, a menos que a embalagem proporcione barreira adequada. Muitos materiais de embalagem flexível proporcionam boa barreira à umidade, mas nenhum é completamente impermeável, limitando assim a vida útil de alimentos de baixa atividade de água (Robertson, 1992). 


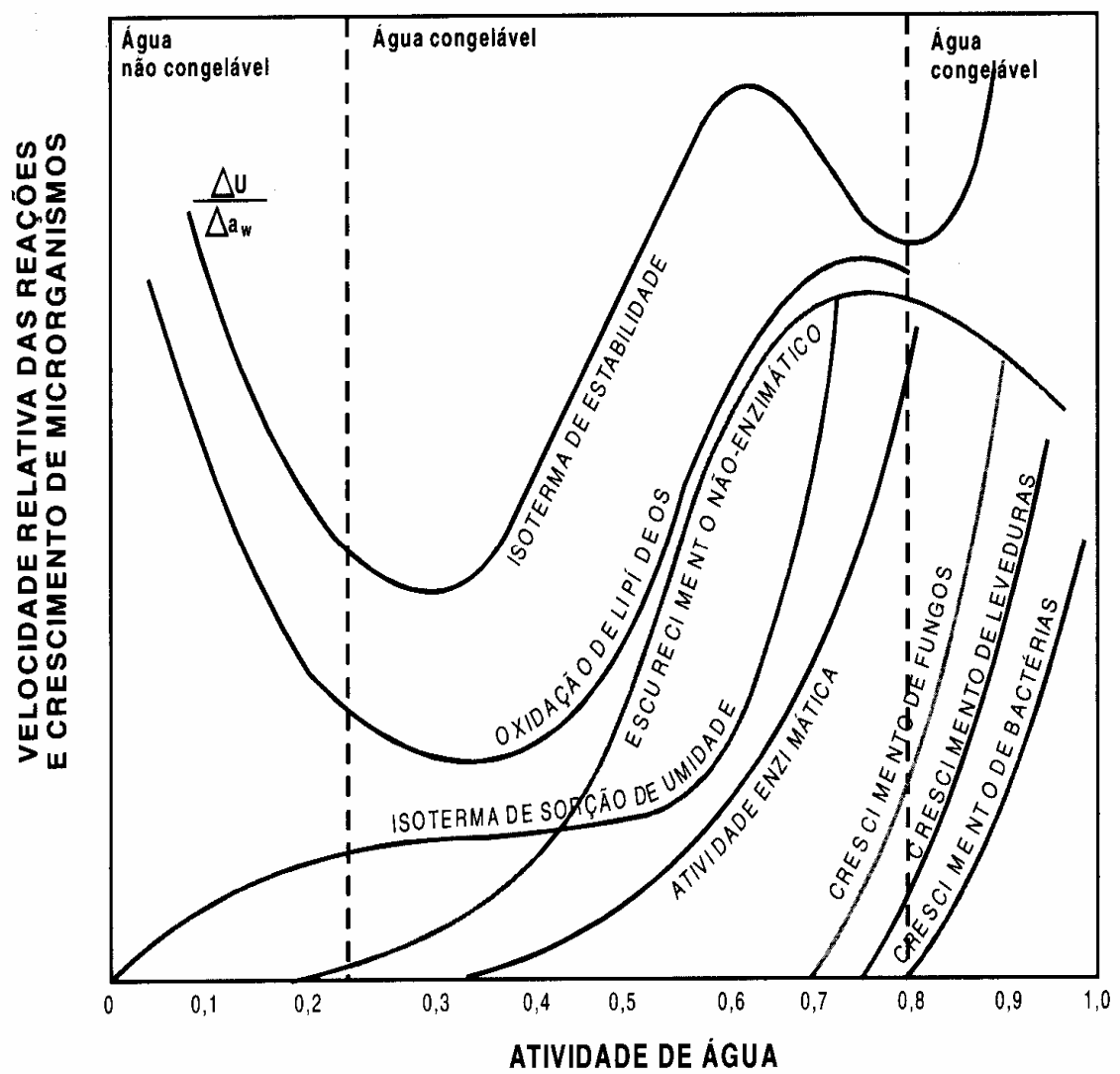

Figura 1 - Velocidade de transformação nos alimentos em função da atividade de água

Fonte: Robertson (1992)

A cor é um dos principais parâmetros indicadores da qualidade da maioria dos alimentos e pode ser utilizada para acompanhar a qualidade oxidativa de carnes frescas. Em carnes, este parâmetro tem importante influência na decisão de compra pelos consumidores e na sua aceitação. É uma importante propriedade funcional e está intimamente relacionada às outras, como $\mathrm{pH}$, capacidade de retenção de água, capacidade emulsificante e a textura. Na maioria dos casos, a cor pode ser considerada indicadora das condições destas propriedades. 
A alteração de cor na carne durante o armazenamento congelado se deve à oxidação da oximioglobina (Genot, 2000), de coloração vermelhobrilhante, à forma de metamioglobina (mioglobina oxidada), de coloração marrom, conforme demonstrado a seguir (Paine \& Paine, 1983).

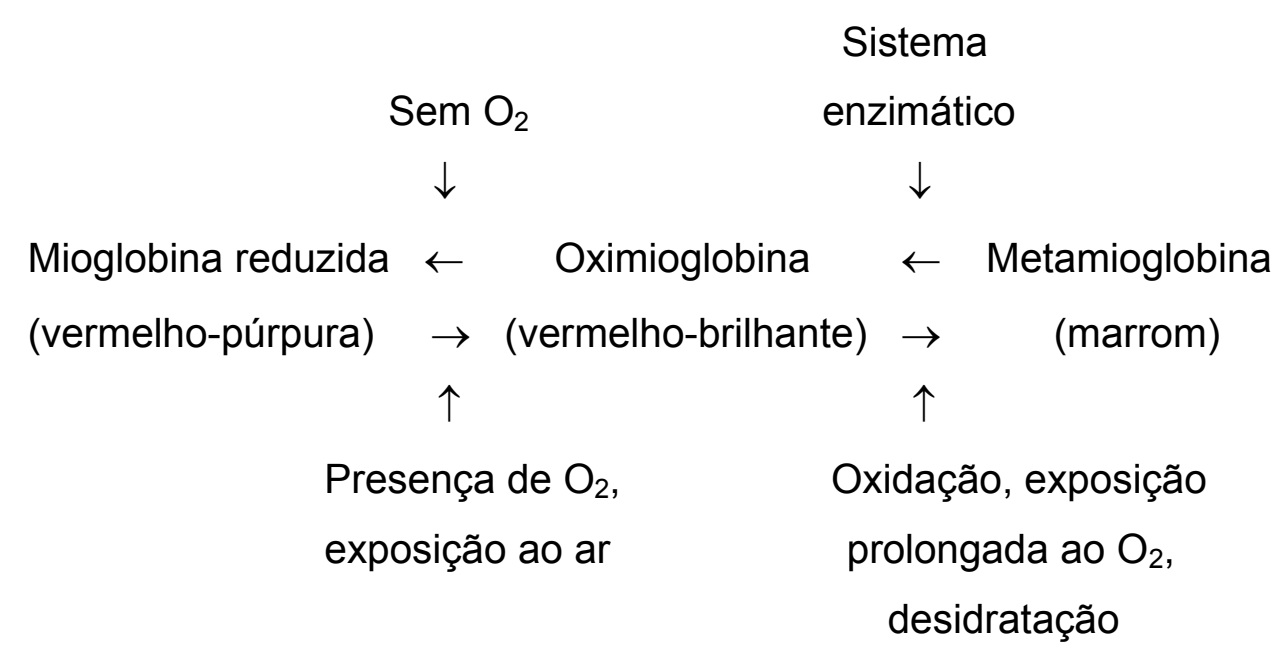

A oxidação da oximioglobina na superfície da carne é um resultado de processos de degradação fotoquímica e térmica. Em carnes congeladas, a fotoxidação destes pigmentos pode ser um grande problema para a aceitação do produto (Genot, 2000).

Carnes com valores de pH menores que 5,7, logo após o abate, podem ser classificadas como carnes PSE (pale, soft e exudative), fenômeno o qual se caracteriza pela desnaturação de proteínas. Esta desnaturação aumenta a birrefringência da carne, causando o desvio da luz, isto é, menos luz é transmitida através das fibras e mais luz acaba sendo dispersa. Isto leva à palidez da carne.

A suscetibilidade da carne à oxidação lipídica tem sido estudada por vários pesquisadores (Mielche e Bertelsen,1994; Gray et al., 1996; Grau et al., 2001) com a finalidade de buscar soluções para amenizar este problema. Com isto, tem sido aplicadas diferentes tecnologias de processamento $\mathrm{e}$ armazenamento para aumentar o tempo de vida útil destes produtos, como 
embalamento a vácuo e com atmosfera modificada, as quais têm-se mostrado efetivas no retardamento da oxidação (Gray et al., 1996).

\subsection{Alimentos Congelados}

O mercado de alimentos congelados apresenta um grande potencial de crescimento, pois seu consumo no Brasil é ainda baixo se comparado ao dos Estados Unidos e de países europeus (Sarantópoulos et al., 2001).

O congelamento é, indiscutivelmente, um dos melhores métodos de conservação de alimentos. Adequadamente conduzido, inibe a deterioração microbiológica, reduz a velocidade de reações químicas, como a atividade enzimática e a oxidação de gorduras, ao mesmo tempo em que retém o sabor, o aroma, a cor e o valor nutritivo dos alimentos e pouco altera a textura dos produtos após o descongelamento.

O congelamento consiste em reduzir a temperatura do alimento (geralmente $\mathrm{a}^{-} 18^{\circ} \mathrm{C}$ ), com a conseqüente cristalização de uma parte da água e alguns dos solutos. Durante o processo de congelamento, a água da solução é transferida para os cristais de gelo, o que resulta na concentração de quase todos os constituintes não aquosos em uma quantidade muito pequena de água não congelada (Robertson, 1992).

A velocidade do processo de congelamento é um fator importante para a qualidade final do produto. No congelamento lento há remoção de água das células e grandes cristais de gelo são formados, podendo ocorrer danos físicos aos tecidos e paredes celulares. Desse modo, durante o processo de congelamento, a estrutura dos tecidos pode ser rompida, provocando exsudação e perda de líquidos ocasionando reações indesejáveis que resultam no desenvolvimento de aroma e sabores indesejáveis, redução do valor nutricional e, principalmente, alterações na textura e aparência dos alimentos após o descongelamento. No congelamento rápido os cristais de gelo formados são menores e a qualidade final do produto tende a ser superior (Halász et al., 1986). 
A formação de gelo durante o congelamento tem aspectos benéficos e prejudiciais. Os benefícios incluem o fortalecimento das estruturas e a remoção da água livre, com a redução da Aa de 0,99 para 0,60 (Van Laack, 1994), em função unicamente da temperatura, independendo da natureza e composição do alimento. Os efeitos prejudiciais incluem as conseqüências da formação de cristais de gelo, como rompimento das estruturas celulares por perfurações, a desidratação parcial do tecido em contato com o cristal de gelo e a concentração dos reagentes (Robertson, 1992).

O congelamento não destrói completamente a microflora do produto, mas o número de células viáveis é reduzido durante o processo e armazenagem. Imediatamente após o congelamento, a eficiência da eliminação de microrganismos varia de acordo com a espécie, sendo que as células que continuam viáveis logo após o congelamento vão, gradualmente, tornando-se inviáveis durante o armazenamento (Sarantópoulos et al., 2001).

O declínio no número de microrganismos viáveis é relativamente rápido a temperaturas abaixo do ponto de congelamento (principalmente em torno de ${ }^{-2}{ }^{\circ} \mathrm{C}$ ), mas é menor a temperaturas inferiores, sendo bastante lento a temperaturas inferiores a ${ }^{-} 20^{\circ} \mathrm{C}$ (Sarantópoulos et al., 2001).

O congelamento é um meio para prolongar a vida útil de carnes e derivados, pois à medida que a temperatura é reduzida as reações físicas, químicas e bioquímicas que acarretam alterações sensoriais nestes produtos passam a ocorrer em baixa velocidade, apesar de não serem completamente paralisadas mesmo quando o alimento é armazenado a ${ }^{-3} 0^{\circ} \mathrm{C}$. Ao mesmo tempo, parte dos microrganismos deterioradores deixa de se multiplicar, sendo que a maioria das bactérias e fungos pára de se desenvolver a ${ }^{-} 8{ }^{\circ} \mathrm{C}$, e parte é destruída (Paine \& Paine, 1983).

De modo geral, os produtos cárneos congelados possuem, como parâmetro de qualidade, o grau de desnaturação protéica que ocorre durante o armazenamento. A desnaturação de proteínas ocorre devido às condições do congelamento e descongelamento e oscilações na temperatura de 
armazenamento. Com a desnaturação, as proteínas perdem a capacidade de reter água, o que irá alterar a textura da carne após o descongelamento e suas propriedades funcionais (Ardito, 1994).

Além da desnaturação de proteínas, podem ocorrer nos produtos cárneos congelados, desidratação da superfície, oxidação de gordura e alterações na cor (Sarantópoulos et al., 2001).

A desidratação superficial ou queima pelo frio (freezer burn) ocorrer quando o produto perde umidade para o ambiente de estocagem através da embalagem. Bolsões de ar que se formam entre a embalagem e o produto também resultam em queima pelo frio, além de dificultar o próprio congelamento atuando como isolante. Contudo, os principais fatores responsáveis pela queima pelo frio são as flutuações de temperatura durante a estocagem e as diferentes etapas de distribuição que podem resultar na formação de cristais de gelo na superfície dos produtos embalados em materiais impermeáveis ao vapor d'água quando há um descongelamento parcial ou total do produto durante a flutuações de temperatura. A queima pelo frio prejudica o aspecto da carne, ressecando sua superfície, comprometendo sua coloração, sabor e textura, além de acarretar perda de peso (Karel et al., 1975).

A deterioração do sabor devido à oxidação das gorduras é um fator limitante da vida útil de carnes e produtos cárneos congelados. As carnes de suínos e aves rancificam mais rapidamente que a bovina, uma vez que apresentam maior porcentagem de gorduras, além de serem mais insaturadas (Olivo \& Shimokomaki, 2001).

A cor da carne congelada é influenciada pelo processamento, material de embalagem, velocidade de congelamento e condições de armazenamento como a temperatura, tempo e luz. Flutuações de temperatura também podem comprometer a cor da superfície de aves rapidamente congeladas (Sarantópoulos et al., 2001). 


\subsection{Embalagens}

A embalagem influencia a qualidade e durabilidade de carnes e aves, pois altera o ambiente ao redor do produto, criando condições que retardam as reações de deterioração. A embalagem previne a evaporação da umidade do produto, evitando perdas de peso e alterações de aparência, textura e aroma. Contudo, a maior alteração no ambiente que circunda o produto, provocada pela embalagem, é quanto à composição gasosa. Esta atmosfera irá determinar a cor do produto, o tipo e a extensão da deterioração microbiológica e a velocidade de oxidação dos seus componentes (Sarantópoulos, 1991).

O uso de embalagens para acondicionamento de carnes, aves e derivados congelados tem como principais objetivos a proteção contra a desidratação e, por isso, deve-se utilizar materiais de embalagem com baixa permeabilidade ao vapor de água. Problemas de queima pelo frio podem ocorrer, mesmo quando embalagens com excelente barreira ao vapor d'água são utilizadas, se o espaço livre não for bastante reduzido (Sarantópoulos et al., 2001).

Também é imprescindível uma boa resistência mecânica, flexibilidade e elasticidade a baixas temperaturas, para se evitar rasgos e perfurações durante todas as etapas de produção, estocagem e comercialização do produto congelado. A perfuração ou rasgo da embalagem pode levar à queima pelo frio e permitir a entrada de oxigênio no interior da embalagem, podendo provocar a oxidação de gorduras e pigmentos resultando na rancificação e alterações na coloração da carne. Os problemas de furos e rasgos são comuns nas embalagens devido ao manuseio inadequado e da própria ação do produto que, após o congelamento, torna-se rígido e com extremidades pontiagudas, que provocam ruptura do filme (Sarantópoulos et al. 2001).

Neste estudo foram utilizadas as embalagens mais comumente encontradas no mercado, que são a bandeja de poliestireno recoberta com filme de PVC. 


\subsubsection{Poliestireno - PS}

O poliestireno é obtido a partir da polimerização do monômero de estireno. É um líquido e o método mais simples de polimerizá-lo é por aquecimento (Sarantópoulos et al., 2002).

As embalagens de poliestireno possuem uma permeabilidade moderada a gases como $\mathrm{O}_{2}$ e a luz e alta permeabilidade aos vapores de água. São muito utilizadas com bandejas para produtos cárneos e fatiados, especialmente em supermercados. Destaca-se a fragilidade da embalagem. O poliestireno é um material rígido e com baixa resistência ao impacto e à flexão, uma vez que sua cadeia principal é relativamente rígida pelo efeito da presença dos anéis benzênicos, características que limitam seu uso (Sarantópoulos et al., 2002).

\section{5. 1 Policloreto de vinila - PVC}

O policloreto de vinila é obtido a partir da polimerização do cloreto de vinila. Este monômero é sintetizado a partir do dicloroetileno, que por sua vez é obtido a partir da reação entre o cloro e o etileno. O etileno é derivado da indústria petroquímica e o cloro é extraído do cloreto de sódio, isto é, é um polímero derivado de $43 \%$ do petróleo e $57 \%$ da fonte inorgânica (Sarantópoulos et al., 2002).

O PVC é a segunda resina plástica mais vendida em todo o mundo, perdendo apenas para o polietileno. Suas aplicações são tão amplas quanto sua versatilidade em propriedades, no entanto possui uma alta permeabilidade à luz, moderada permeabilidade ao oxigênio e a vapores de água. No segmento de embalagem, o PVC é usado em filmes plastificados esticáveis, muito empregados como envoltórios de produtos in natura, como carnes, frango e frutas, para a venda em supermercados e para uso caseiro (Sarantópoulos et al., 2002).

\subsection{Caracterização das fontes lipídicas}

Apesar da diferença física dos óleos e gorduras, que se deve 
principalmente ao ponto de fusão das gorduras ser maior do que dos óleos, a indústria avícola atribui a ambos o termo gorduras. As principais fontes lipídicas utilizadas na formulação de rações para frangos de corte são: óleo de soja, óleo ácido de soja, óleo de vísceras de aves, sebo bovino e gordura suína. Neste trabalho algumas destas fontes foram avaliadas.

\subsection{1 Óleo de soja}

A obtenção do óleo de soja segue o processo: preparação dos grãos e extração por solvente.

O preparo dos grãos para a extração inicia-se com a quebra dos mesmos, seguido de condicionamento e laminação. A quebra dos grãos é efetuada em quebradores de rolo, que consistem um ou dois pares de cilindros ranhurados. A soja deve estar limpa, livre de impurezas, visando melhorar a qualidade da massa de grãos e reduzir o desgaste dos equipamentos, também deve estar seca e madura. Deve-se garantir a uniformidade das partículas após a quebra para permitir uma melhor qualidade, bem como rendimento, e a não formação de pó, que poderiam causar inconvenientes durante e no fim do processo de industrialização. Após a quebra, a soja passa para o condicionamento, o qual visa tornar o pedaço de grão um material mais plástico, fácil de ser laminado e ajustar-lhe a umidade. A laminação facilita a extração por solvente, tanto pelo efeito de ruptura das células e exposição do óleo, como pela redução das distâncias que solvente e óleo devem percorrer ao se difundirem para dentro e fora do grão durante o processo de extração.

Após o preparo dos grãos, é iniciada a extração que ocorre por solvente hexano e consiste na sua penetração nos corpos lipídicos do cotilédone, solubilização do óleo e difusão do óleo-hexano para fora, resultando em uma solução solvente + óleo, a qual é chamada de miscela. O tempo de extração está diretamente ligado à espessura das lâminas.

O óleo é separado do solvente por destilação, deste resultando o óleo bruto de soja, o qual poderá passar pelo refino, obtendo-se o óleo de soja 
refinado.

O processo de refino compõe-se de degomagem, neutralização, clarificação e desodorização. A degomagem remove os fosfolipídios do óleo bruto de soja, devido à adição de 1 a $3 \%$ de água a $70^{\circ} \mathrm{C}$ que os entumesce, separando-os por centrifugação. Neste processo, são obtidos o óleo degomado e o resíduo goma, onde está a lecitina. O óleo bruto e o degomado de soja são os mais utilizados nas dietas de frangos de corte, por serem de custo mais barato. Além disso, caracteriza-se pela alta concentração de ácidos graxos insaturados, principalmente linoléico e linolênico.

A degomagem é seguida pelo processo de neutralização. Consiste na remoção dos ácidos graxos livres do óleo degomado. Os ácidos graxos são removidos pela reação com o hidróxido de sódio. Há a saponificação dos ácidos graxos livres e sua remoção por centrifugação, além da remoção de alguns pigmentos. Nesta etapa é obtido o óleo neutralizado e a borra da neutralização. Esse resíduo é chamado de "soapstock" do qual poderá ser obtido o óleo ácido de soja. Após a neutralização o óleo passa pelo processo de clarificação com argilas e de desodorização para finalmente ser embalado e comercializado.

Na tabela 1, são apresentados o perfil de ácidos graxos do óleo de soja.

Tabela 1. Perfil dos ácidos graxos do óleo de soja (\%)

\begin{tabular}{lccc}
\hline Ácidos graxos & $\begin{array}{c}\text { Ketels \& De } \\
\text { Groote (1989) }\end{array}$ & $\begin{array}{c}\text { Zollitsch et al. } \\
(1997)\end{array}$ & Liu (1999) \\
\hline Ác. Palmítico (16:0) & 10,7 & 10,4 & 11,0 \\
Ac. Esteárico (18:0) & 1,8 & 3,7 & 4,0 \\
Ác. Oléico (18:1) & 22,3 & 21,6 & 23,4 \\
Ác. Linoléico (18:2) & 51,9 & 50,6 & 53,2 \\
Ac. Linolênico (18:3) & 7,0 & 11,8 & 7,8 \\
Saturados & 12,6 & 14,5 & 15,2 \\
Insaturados & 81,3 & 84,2 & 84,5 \\
\hline
\end{tabular}




\subsection{2 Óleo ácido de soja}

É um subproduto da indústria de óleo de soja e é obtido através da hidrólise com ácido sulfúrico da borra de neutralização ou "soapstock" e é um importante produto para a formulação de ração para animais (Erickson, 1995).

O "soapstock" consiste de sais orgânicos de sódio, formados a partir da reação entre ácidos graxos livres e hidróxido de sódio.

$\mathrm{Na}$ tabela 2, é apresentado o perfil dos ácidos graxos do óleo ácido segundo Young (1961) e Renner \& Hill (1961).

Tabela 2. Perfil dos ácidos graxos do óleo ácido de soja (\%)

\begin{tabular}{lcc}
\hline Ácidos graxos & Young (1961) & Renner \& Hill (1961) \\
\hline Ác. Palmítico (16:0) & 12,3 & 19,2 \\
Ac. Esteárico (18:0) & 4,5 & 4,6 \\
Ác. Oléico (18:1) & 30,0 & 17,6 \\
Ác. Linoléico (18:2) & 46,7 & 51,2 \\
Ac. Linolênico (18:3) & 6,4 & 7,1 \\
Saturados & 16,8 & 23,8 \\
Insaturados & 83,1 & 75,9 \\
\hline
\end{tabular}

\subsection{3 Óleo de vísceras de aves}

A farinha e o óleo de vísceras de aves são originários das vísceras, pés, cabeças, restos do processo de separação mecânica da carne e aves condenadas pelos serviços oficiais de inspeção. Os resíduos são direcionados ao setor de subprodutos para serem processados em um cozedor.

O cozedor para o processamento das vísceras é um cilindro revestido com chapas de aço espessas, compartimentos de carga e descarga, pás giratórias internas e entrada para vapor de água. Neste processo, o tempo de cocção, a pressão e a temperatura de funcionamento afetam o rendimento e a qualidade da farinha de vísceras e do óleo de vísceras de aves (Maffi, 1993).

Após o processamento, todo conteúdo do cozedor é descarregado em 
um percolador, separando as vísceras cozidas do óleo e da água. As vísceras seguem para uma prensa para a separação do restante do óleo. O óleo e a água do percolador passam por tanques de lavagem para serem separados. $O$ óleo dos tanques de lavagem se junta ao proveniente da prensa, para ser filtrado e armazenado (Neto, 1994).

O óleo de vísceras de aves (Tabela 3), quando comparado ao do óleo de soja, possui maior porcentagem dos ácidos graxos palmítico e oléico, e menor teor dos ácidos graxos linoléico e linolênico. A grande diferença entre estas matérias graxas é a presença do ácido graxo palmitoléico no óleo de vísceras de aves (Waldroup, 1995), apesar do menor teor de insaturados.

Tabela 3. Perfil dos ácidos graxos do óleo de vísceras de aves (\%)

\begin{tabular}{lccc}
\hline Ácidos graxos & $\begin{array}{c}\text { Brue \& Latshaw } \\
(1985)\end{array}$ & $\begin{array}{c}\text { Waldroup et al. } \\
(1995)\end{array}$ & Racanicci (2004) \\
\hline Ác. Palmítico (16:0) & 26,8 & 23,2 & 27,70 \\
Ac. Palmitoléico (16:1) & 9,0 & 7,1 & 8,60 \\
Ac. Esteárico (18:0) & 2,4 & 6,4 & 6,60 \\
Ác. Oléico (18:1) & 42,9 & 43,0 & 38,20 \\
Ác. Linoléico (18:2) & 16,9 & 17,9 & 16,20 \\
Ac. Linolênico (18:3) & 0,9 & 0,6 & 0,03 \\
Saturados & 30,3 & 31,0 & 35,07 \\
Insaturados & 69,7 & 69,2 & 63,04
\end{tabular}




\section{MATERIAL E MÉTODOS}

\subsection{Criação dos Animais}

As aves foram criadas de 1 a 42 dias no Departamento de Zootecnia da Escola Superior de Agricultura "Luiz de Queiroz", USP - Piracicaba em galpão experimental, com 36 boxes de $3 \mathrm{~m}$ de comprimento por 1,5m de largura, com área de $4,5 \mathrm{~m}^{2}$, distribuídos em 2 fileiras longitudinais, separadas por um corredor de $2 \mathrm{~m}$ de largura. Cada box era provido de um bebedouro, um comedouro e uma lâmpada infravermelha de 250 watts para aquecimento inicial dos pintos. Aos 14 dias de idade todos estes equipamentos, inclusive as lâmpadas, foram retirados e substituídos pelos utilizados para aves adultas.

O experimento consistiu de 6 tratamentos e 6 repetições em blocos casualizados, constituídos de 46 pintos machos da linhagem comercial AgRoss por box. As aves e as rações foram pesadas semanalmente, para se obter o ganho de peso médio, o peso médio das aves, o consumo de ração e conversão alimentar, como parte do acompanhamento experimental do projeto que deu origem a essa pesquisa.

O nível nutricional das rações utilizadas foi calculado segundo Rostagno (2000) (Tabelas 4, 5, 6 e 7). As rações foram isocalóricas e suas misturas constituíram os tratamentos experimentais:

- $\quad$ OS - óleo bruto de soja;

- $\quad$ FR - óleo de vísceras de aves;

- $\quad \mathrm{AC}-$ óleo ácido de soja;

- OS50FR50 - mistura de 50\% de óleo bruto de soja e 50\% de óleo de vísceras de aves; 
- OS25AC75 - mistura de $25 \%$ óleo bruto de soja e $75 \%$ óleo ácido de soja;

- $\quad$ OS50AC50 - mistura de $50 \%$ de óleo bruto de soja e $50 \%$ de óleo de ácido de soja.

O óleo de soja e o óleo ácido de soja foram cedidos pela Agropecuária Ninho Verde e o óleo de vísceras foi cedido pela Avícola Frango Oeste.

\subsection{Abate e ensaio de armazenamento congelado}

As aves foram abatidas com 42 dias de idade, no Abatedouro Experimental da Faculdade UNESP - Botucatu, onde também foram depenadas, evisceradas, separadas em partes e resfriadas em câmara fria. Posteriormente a carne foi transportada para Piracicaba em caixas de isopor com gelo, para a embalagem e início do experimento.

No Laboratório de Carnes do Departamento de Agroindústria, Alimentos e Nutrição, ESALQ/USP, as sobrecoxas sem pele foram embaladas em bandejas de poliestireno recobertas com filme PVC, sendo que em cada bandeja foram colocadas 3 sobrecoxas, para cada tratamento. Após este procedimento, a carne foi colocada em congelador a uma temperatura aproximada de ${ }^{-} 18^{\circ} \mathrm{C} \pm 2^{\circ} \mathrm{C}$ no Laboratório de Óleos e Gorduras do Departamento. O produto foi armazenado por 9 meses e, analisado em triplicata, quanto às suas características químicas, físicas e sensoriais para os seis tratamentos, nos meses $0,1,2,4,6$ e 9 de armazenamento.

\subsection{Caracterização química das fontes lipídicas}

As diferentes fontes lipídicas fornecidas na ração dos animais foram analisadas qualitativamente através das determinações do índice de peróxido, e acidez, absortividade na faixa do ultravioleta em 232 e $270 \mathrm{~nm}$.

Também foi analisado o perfil de ácidos graxos, em cromatógrafo gasoso. 
Tabela 4. Composição das dietas na fase pré-inicial

\begin{tabular}{|c|c|c|c|c|c|c|}
\hline Ingredientes (\%) & OS & FR & $A C$ & OS25AC75 & OS50AC50 & OS50FR50 \\
\hline Milho & 49,37 & 49,11 & 47,06 & 48,36 & 49,32 & 49,17 \\
\hline Farelo de soja & 42,72 & 42,77 & 43,15 & 42,91 & 42,73 & 42,76 \\
\hline os & 3,98 & - & - & - & - & - \\
\hline FR & - & 4,19 & - & - & - & - \\
\hline$A C$ & - & - & 5,86 & - & - & - \\
\hline OS25AC75 & - & - & - & 4,80 & - & - \\
\hline OS50AC50 & - & - & - & - & 4,02 & - \\
\hline OS50FR50 & - & - & - & - & - & 4,14 \\
\hline Fosfato bicálcico & 1,86 & 1,86 & 1,86 & 1,86 & 1,86 & 1,86 \\
\hline Calcário calcítico & 0,97 & 0,97 & 0,97 & 0,97 & 0,97 & 0,97 \\
\hline Sal & 0,50 & 0,50 & 0,50 & 0,50 & 0,50 & 0,50 \\
\hline DL-Metionina & 0,20 & 0,20 & 0,20 & 0,20 & 0,20 & 0,20 \\
\hline Suplemento & 0,30 & 0,30 & 0,30 & 0,30 & 0,30 & 0,30 \\
\hline vitamínico $^{1}$ & & & & & & \\
\hline Suplemento mineral ${ }^{2}$ & 0,05 & 0,05 & 0,05 & 0,05 & 0,05 & 0,05 \\
\hline Cloreto colina $60 \%$ & 0,05 & 0,05 & 0,05 & 0,05 & 0,05 & 0,05 \\
\hline Nutrientes & \multicolumn{6}{|c|}{ Níveis Calculados } \\
\hline EM (kcal/kg) & 2960 & 2960 & 2960 & 2960 & 2960 & 2960 \\
\hline PB (\%) & 24,0 & 24,0 & 24,0 & 24,0 & 24,0 & 24,0 \\
\hline Metionina + & 0,92 & 0,92 & 0,92 & 0,92 & 0,92 & 0,92 \\
\hline \multicolumn{7}{|l|}{ Cistina (\%) } \\
\hline Lisina (\%) & 1,31 & 1,31 & 1,31 & 1,31 & 1,31 & 1,31 \\
\hline Fósforo disp. (\%) & 0,46 & 0,46 & 0,46 & 0,46 & 0,46 & 0,46 \\
\hline Cálcio (\%) & 0,98 & 0,98 & 0,98 & 0,98 & 0,98 & 0,98 \\
\hline
\end{tabular}

1-Concentração por kg de ração: Ácido fólico, $1 \mathrm{mg}$; ácido pantotênico, $15 \mathrm{mg}$; antioxidante, 22,5 mg; biotina, $60 \mathrm{mg}$; colina, $400 \mathrm{mg}$; niacina, $40 \mathrm{mg}$, selênio, 0,3 mg; vitamina A, $8.000 \mathrm{Ul}$; vitamina B1, 1,8 mg; vitamina B12, $12 \mathrm{mcg}$; vitamina B2, $6 \mathrm{mg}$; vitamina B6, 2,8 mg; vitamina D3, $2.000 \mathrm{Ul}$; vitamina $\mathrm{E}, 15 \mathrm{Ul}$; vitamina $\mathrm{K}, 1,8 \mathrm{mg}$.

2- Concentração por kg de ração: Manganês 75 mg; cobre 8 mg; zinco 50 mg; ferro 50 $\mathrm{mg}$; iodo $0,75 \mathrm{mg}$. 
Tabela 5. Composição das dietas na fase inicial

\begin{tabular}{|c|c|c|c|c|c|c|}
\hline Ingredientes (\%) & OS & FR & $A C$ & OS25AC75 & OS50AC50 & OS50FR50 \\
\hline Milho & 58,62 & 58,30 & 56,69 & 57,77 & 58,39 & 58,28 \\
\hline Farelo de soja & 34,94 & 35,00 & 35,31 & 35,10 & 34,99 & 35,00 \\
\hline OS & 2,34 & - & - & - & - & - \\
\hline FR & - & 2,60 & - & - & - & - \\
\hline AC & - & - & 3,90 & - & - & - \\
\hline OS25AC75 & - & - & - & 3,03 & - & - \\
\hline OS50AC50 & - & - & - & - & 2,52 & - \\
\hline OS50FR50 & - & - & - & - & - & 2,62 \\
\hline Fosfato bicálcico & 1,82 & 1,82 & 1,82 & 1,82 & 1,82 & 1,82 \\
\hline Calcário calcítico & 0,98 & 0,98 & 0,98 & 0,98 & 0,98 & 0,98 \\
\hline Sal & 0,50 & 0,50 & 0,50 & 0,50 & 0,50 & 0,50 \\
\hline Lisina $\mathrm{HCl}$ & 0,18 & 0,18 & 0,18 & 0,18 & 0,18 & 0,18 \\
\hline DL-Metionina & 0,23 & 0,23 & 0,23 & 0,23 & 0,23 & 0,23 \\
\hline Suplemento & 0,30 & 0,30 & 0,30 & 0,30 & 0,30 & 0,30 \\
\hline vitamínico $^{1}$ & & & & & & \\
\hline Suplemento mineral $\left.\right|^{2}$ & 0,05 & 0,05 & 0,05 & 0,05 & 0,05 & 0,05 \\
\hline Cloreto colina $60 \%$ & 0,04 & 0,04 & 0,04 & 0,04 & 0,04 & 0,04 \\
\hline Nutrientes & \multicolumn{6}{|c|}{ Níveis Calculados } \\
\hline EM (kcal/kg) & 3000 & 3000 & 3000 & 3000 & 3000 & 3000 \\
\hline PB (\%) & 21,4 & 21,4 & 21,4 & 21,4 & 21,4 & 21,4 \\
\hline Metionina + & 0,89 & 0,89 & 0,89 & 0,89 & 0,89 & 0,89 \\
\hline \multicolumn{7}{|l|}{ Cistina (\%) } \\
\hline Lisina (\%) & 1,26 & 1,26 & 1,26 & 1,26 & 1,26 & 1,26 \\
\hline Fósforo disp. (\%) & 0,45 & 0,45 & 0,45 & 0,45 & 0,45 & 0,45 \\
\hline Cálcio (\%) & 0,96 & 0,96 & 0,96 & 0,96 & 0,96 & 0,96 \\
\hline
\end{tabular}

1-Concentração por kg de ração: Ácido fólico, $1 \mathrm{mg}$; ácido pantotênico, $15 \mathrm{mg}$; antioxidante, 22,5 mg; biotina, $60 \mathrm{mg}$; colina, $400 \mathrm{mg}$; niacina, $40 \mathrm{mg}$, selênio, 0,3 mg; vitamina A, $8.000 \mathrm{Ul}$; vitamina B1, 1,8 mg; vitamina B12, $12 \mathrm{mcg}$; vitamina B2, $6 \mathrm{mg}$; vitamina B6, 2,8 mg; vitamina D3, $2.000 \mathrm{Ul}$; vitamina E, $15 \mathrm{UI}$; vitamina $\mathrm{K}, 1,8 \mathrm{mg}$.

2- Concentração por kg de ração: Manganês $75 \mathrm{mg}$; cobre $8 \mathrm{mg}$; zinco 50 mg; ferro 50 $\mathrm{mg}$; iodo $0,75 \mathrm{mg}$. 
Tabela 6. Composição das dietas na fase de crescimento

\begin{tabular}{|c|c|c|c|c|c|c|}
\hline Ingredientes (\%) & OS & FR & $\mathrm{AC}$ & OS25AC75 & OS50AC50 & OS50FR50 \\
\hline Milho & 62,88 & 62,79 & 61,64 & 62,01 & 62,57 & 62,56 \\
\hline Farelo de soja & 30,07 & 30,08 & 30,30 & 30,23 & 30,13 & 30,13 \\
\hline OS & 3,21 & - & - & - & - & - \\
\hline FR & - & 3,29 & - & - & - & - \\
\hline$A C$ & - & - & 4,22 & - & - & - \\
\hline OS25AC75 & - & - & - & 3,92 & - & - \\
\hline OS50AC50 & - & - & - & - & 3,46 & - \\
\hline OS50FR50 & - & - & - & - & - & 3,47 \\
\hline Fosfato bicálcico & 1,61 & 1,61 & 1,61 & 1,61 & 1,61 & 1,61 \\
\hline Calcário calcítico & 0,93 & 0,93 & 0,93 & 0,93 & 0,93 & 0,93 \\
\hline Sal & 0,50 & 0,50 & 0,50 & 0,50 & 0,50 & 0,50 \\
\hline Lisina & 0,20 & 0,20 & 0,20 & 0,20 & 0,20 & 0,20 \\
\hline DL-Metionina & 0,21 & 0,21 & 0,21 & 0,21 & 0,21 & 0,21 \\
\hline $\begin{array}{l}\text { Suplemento } \\
\text { vitamínico }^{1}\end{array}$ & 0,30 & 0,30 & 0,30 & 0,30 & 0,30 & 0,30 \\
\hline Suplemento mineral $^{2}$ & 0,05 & 0,05 & 0,05 & 0,05 & 0,05 & 0,05 \\
\hline Cloreto colina $60 \%$ & 0,04 & 0,04 & 0,04 & 0,04 & 0,04 & 0,04 \\
\hline Nutrientes & \multicolumn{6}{|c|}{ Níveis Calculados } \\
\hline EM (kcal/kg) & 3100 & 3100 & 3100 & 3100 & 3100 & 3100 \\
\hline PB (\%) & 19,5 & 19,5 & 19,5 & 19,5 & 19,5 & 19,5 \\
\hline Metionina + & 0,82 & 0,82 & 0,82 & 0,82 & 0,82 & 0,82 \\
\hline Cistina (\%) & & & & & & \\
\hline Lisina (\%) & 1,15 & 1,15 & 1,15 & 1,15 & 1,15 & 1,15 \\
\hline Fósforo disp. (\%) & 0,40 & 0,40 & 0,40 & 0,40 & 0,40 & 0,40 \\
\hline Cálcio (\%) & 0,87 & 0,87 & 0,87 & 0,87 & 0,87 & 0,87 \\
\hline
\end{tabular}

1-Concentração por $\mathrm{kg}$ de ração: Ácido fólico, 0,7 mg; ácido pantotênico, $13 \mathrm{mg}$; antioxidante, $15 \mathrm{mg}$; colina $300 \mathrm{mg}$; niacina, $3,5 \mathrm{mg}$; selênio, 0,3 mg; vitamina A, 7.000 UI; vitamina B1, 1,6 mg; vitamina B12, $10 \mathrm{mcg}$; vitamina B2, $5 \mathrm{mg}$; vitamina B6, 2,6 mg; vitamina D3, $1500 \mathrm{UI}$; vitamina E, $12 \mathrm{UI}$; vitamina $\mathrm{K}, 1,5 \mathrm{mg}$.

2- Concentração por kg de ração: Manganês $75 \mathrm{mg}$; cobre $8 \mathrm{mg}$; zinco 50 mg; ferro 50 $\mathrm{mg}$; iodo $0,75 \mathrm{mg}$. 
Tabela 7. Composição das dietas na fase final

\begin{tabular}{|c|c|c|c|c|c|c|}
\hline Ingredientes (\%) & OS & FR & $A C$ & OS25AC75 & OS50AC50 & OS50FR50 \\
\hline Milho & 65,91 & 65,82 & 64,35 & 65,04 & 65,52 & 65,46 \\
\hline Farelo de soja & 26,19 & 26,20 & 26,48 & 26,35 & 26,26 & 26,27 \\
\hline OS & 4,06 & - & - & - & - & - \\
\hline FR & - & 4,14 & - & - & - & - \\
\hline AC & - & - & 5,33 & - & - & - \\
\hline OS25AC75 & - & - & - & 4,77 & - & - \\
\hline OS50AC50 & - & - & - & - & 4,38 & - \\
\hline OS50FR50 & - & - & - & - & - & 4,43 \\
\hline Fosfato bicálcico & 1,47 & 1,47 & 1,47 & 1,47 & 1,47 & 1,47 \\
\hline Calcário calcítico & 1,04 & 1,04 & 1,04 & 1,04 & 1,04 & 1,04 \\
\hline Sal & 0,50 & 0,50 & 0,50 & 0,50 & 0,50 & 0,50 \\
\hline Lisina & 0,24 & 0,24 & 0,24 & 0,24 & 0,24 & 0,24 \\
\hline DL-Metionina & 0,20 & 0,20 & 0,20 & 0,20 & 0,20 & 0,20 \\
\hline Suplemento & 0,30 & 0,30 & 0,30 & 0,30 & 0,30 & 0,30 \\
\hline vitamínico ${ }^{1}$ & & & & & & \\
\hline Suplemento mineral $\left.\right|^{2}$ & 0,05 & 0,05 & 0,05 & 0,05 & 0,05 & 0,05 \\
\hline Cloreto colina $60 \%$ & 0,04 & 0,04 & 0,04 & 0,04 & 0,04 & 0,04 \\
\hline Nutrientes & \multicolumn{6}{|c|}{ Níveis Calculados } \\
\hline EM (kcal/kg) & 3200 & 3200 & 3200 & 3200 & 3200 & 3200 \\
\hline PB (\%) & 18,0 & 18,0 & 18,0 & 18,0 & 18,0 & 18,0 \\
\hline Metionina + & 0,77 & 0,77 & 0,77 & 0,77 & 0,77 & 0,77 \\
\hline \multicolumn{7}{|l|}{ Cistina (\%) } \\
\hline Lisina (\%) & 1,08 & 1,08 & 1,08 & 1,08 & 1,08 & 1,08 \\
\hline Fósforo disp. (\%) & 0,37 & 0,37 & 0,37 & 0,37 & 0,37 & 0,37 \\
\hline Cálcio (\%) & 0,87 & 0,87 & 0,87 & 0,87 & 0,87 & 0,87 \\
\hline
\end{tabular}

1-Concentração por kg de ração: Ácido fólico, 0,7 mg; ácido pantotênico, $13 \mathrm{mg}$; antioxidante, 15,0 mg; colina, $300 \mathrm{mg}$; niacina, $3,5 \mathrm{mg}$, selênio, 0,3 mg; vitamina $A$, $7.000 \mathrm{UI}$; vitamina B1, 1,6 mg; vitamina B12, $10 \mathrm{mcg}$; vitamina B2, $5 \mathrm{mg}$; vitamina B6, 2,6 mg; vitamina D3, $1500 \mathrm{Ul}$; vitamina E, $12 \mathrm{Ul}$; vitamina $\mathrm{K}, 1,5 \mathrm{mg}$.

2- Concentração por kg de ração: Manganês $75 \mathrm{mg}$; cobre $8 \mathrm{mg}$; zinco $50 \mathrm{mg}$; ferro 50 $\mathrm{mg}$; iodo $0,75 \mathrm{mg}$. 


\subsection{Caracterização química, física e sensorial da carne de frango}

A caracterização da carne foi realizada no início do experimento no Laboratório de Óleos e Gorduras do Departamento de Agroindústria, Alimentos e Nutrição da Escola Superior de Agricultura "Luiz de Queiroz", USP Piracicaba, através da determinação da composição centesimal. A análise do perfil de ácidos graxos foi realizada nos meses 0, 4 e 9 de armazenamento. Para acompanhar a estabilidade oxidativa da carne durante o período de armazenamento foram feitas análises de TBA, cor e pH nos meses 0, 1, 2, 4, 6 e 9 de armazenamento. Concomitantemente realizou-se a análise sensorial.

\subsection{Métodos}

\subsubsection{Composição centesimal}

As sobrecoxas de frango sem pele foram caracterizadas através do teor de gordura, segundo a metodologia $n^{\circ} 1.122$ de Soxhlet (IUPAC, 1979), pelo teor de proteína bruta, método $n^{\circ} 950.08$, pelo grau de umidade, método $\mathrm{n}^{\circ}$ 950.46 e teor de cinza, método $n^{\circ} 920.153$, segundo AOAC (1995), e o teor de carboidratos totais foi calculado pela diferença entre 100 e a soma dos demais componentes.

\subsection{2 Índice de peróxido}

Verificado segundo as normas da AOCS - Cd8b-90 (1997), através da dissolução de amostras de $5 \mathrm{~g}$ de óleo em solução de ácido acético e isooctano e adição de solução saturada de iodeto de potássio, seguida de titulação de tiossulfato de sódio $0,1 \mathrm{~N}$. O volume gasto após adição de solução indicadora de amido, indica a concentração de peróxidos em meq/Kg, através da fórmula:

Índice de peróxido $(\mathrm{meq} / \mathrm{Kg})=(\mathrm{A}-\mathrm{B}) \times \mathrm{N} \times 1000 / \mathrm{P}$ em que:

$A=$ volume de tiossulfato gasto na titulação da amostra 
$B=$ volume de tiossulfato gasto na titulação do branco

$\mathrm{N}=$ normalidade da solução de tiossulfato de sódio

$P=$ peso da amostra em gramas

\subsubsection{Acidez}

Foi realizado segundo as normas da AOCS - Ca 5a-40 (1997), com dissolução de amostras de $5 \mathrm{~g}$ de óleo em álcool etílico a quente $\left(60-65^{\circ} \mathrm{C}\right) \mathrm{e}$ titulação com solução de hidróxido de sódio $0,1 \mathrm{~N}$. O volume gasto indicou a acidez em $\mathrm{mg} \mathrm{KOH} / \mathrm{g}$, através da fórmula:

Acidez $\mathrm{mg} \mathrm{KOH} / \mathrm{g}=\mathrm{ml}$ de hidróxido de sódio $\times 10 \times \mathrm{N} / \mathrm{P}$

em que:

$\mathrm{N}$ = normalidade da solução hidróxido de sódio

$\mathrm{P}=$ peso da amostra $(\mathrm{g})$

\subsubsection{Absortividade na faixa do ultravioleta em 232 e $270 \mathrm{~nm}$}

Foi determinada segundo a metodologia NDG C-40 (SSOG, 1976), a qual se baseia na determinação da absorbância de óleos e gorduras na faixa do ultravioleta, dando uma indicação de sua pureza e deterioração, revelando a presença de produtos de oxidação e de dienos e trienos conjugados. Pesa-se $0,2 \mathrm{~g}$ de amostra em um balão volumétrico de $25 \mathrm{~mL}$, completando o volume com isoctano. Desta feita, o conteúdo do balão é transferido para uma célula de quartzo para fazer as leituras em 232 e $270 \mathrm{~nm}$, utilizando isoctano como branco. Os resultados nos comprimentos de onda expressos em absortividade foram dados pela fórmula:

Absortividade $=\mathrm{A} /($ c.e $)$

em que:

A = absorbância registrada no comprimento de onda utilizado

c = concentração (g 100 mL-1) da solução amostrada

e $=$ largura da cubeta utilizada $(\mathrm{cm})$ 


\subsubsection{Perfil de ácidos graxos}

A extração dos lipídios da carne da sobrecoxa foi realizada de acordo com a metodologia de Bligh \& Dyer (1959), segundo algumas modificações propostas por Christie (1982) e Smedes \& Thomasen (1996). Foram pesados $10 \mathrm{~g}$ da amostra úmida triturada (com cerca de $70 \%$ de umidade) e o tecido foi homogeneizado durante 5 minutos com uma mistura de $10 \mathrm{~mL}$ de clorofórmio e $20 \mathrm{~mL}$ de metanol em uma mesa agitadora. Em seguida, foram adicionados mais $10 \mathrm{~mL}$ de clorofórmio e procedeu-se a agitação por mais 5 minutos. A mistura foi filtrada e o resíduo do papel de filtro foi lavado com mais $10 \mathrm{~mL}$ de clorofórmio para um melhor rendimento da extração. O filtrado foi transferido para um funil de separação de $250 \mathrm{~mL}$, adicionado de $10 \mathrm{~mL}$ de solução de $\mathrm{HCl}$ $0,88 \%$ e agitado vigorosamente. Formou-se um sistema bifásico e a fase inferior, contendo os lipídios purificados diluídos em clorofórmio, foi filtrada em papel de filtro contendo sulfato de sódio anidro e coletada em balão volumétrico previamente pesado. O solvente foi totalmente evaporado utilizando-se gás nitrogênio.

O óleo extraído da carne da sobrecoxa foi esterificado e metilado de acordo com a metodologia de Hartman \& Lago (1973). Foram pesados 100-200 $\mathrm{mg}$ de óleo em frascos de $50 \mathrm{~mL}$ providos de condensador para saponificação com $5 \mathrm{~mL}$ de solução metanólica $0,5 \mathrm{~N}$ de KOH sob fervura. Adicionaram-se 15 $\mathrm{mL}$ do reagente de esterificação à solução quente e a mistura foi aquecida sob refluxo por 3 minutos. Em seguida, transferiu-se a amostra para um funil de separação usando $25 \mathrm{~mL}$ de éter de petróleo e $50 \mathrm{~mL}$ de água destilada. A fase inferior, aquosa, foi descartada e a fase etérea foi lavada duas vezes com 25 $\mathrm{mL}$ de água. As amostras foram então transferidas para frascos âmbar e tampados e guardadas $\mathrm{a}^{-} 18^{\circ} \mathrm{C}$ até o momento da injeção em cromatógrafo gasoso.

Para determinação do perfil dos ácidos graxos nas amostras metiladas foi usado um cromatógrafo gasoso (Hewlett 5890 Series II) com detector FID (flame ionization detector) e coluna capilar de sílica de $60 \mathrm{~m} \times 0,25 \mathrm{~mm} \times 0,25$ 
$\mu \mathrm{m}$ (DB - 23). As condições de injeção foram: temperatura do forno a $130{ }^{\circ} \mathrm{C}$ por $1 \mathrm{~min}, 130^{\circ} \mathrm{C}$ a $170^{\circ} \mathrm{C}$ (taxa de $6,5^{\circ} \mathrm{C} / \mathrm{min}$ ), de $170{ }^{\circ} \mathrm{C}$ a $215^{\circ} \mathrm{C}$ (taxa de $\left.2,75^{\circ} \mathrm{C} / \mathrm{min}\right), 215^{\circ} \mathrm{C}$ por $12 \mathrm{~min}$, de $215^{\circ} \mathrm{C}$ a $230^{\circ} \mathrm{C}\left(40{ }^{\circ} \mathrm{C} / \mathrm{min}\right)$ e de $230{ }^{\circ} \mathrm{C}$ por $3 \mathrm{~min}$; temperatura de injeção (split), $270^{\circ} \mathrm{C}$; temperatura do FID, $280^{\circ} \mathrm{C}$; volume de injeção, 0,2 mcL; gás hélio de arraste com fluxo de 1,6 mL/min. As amostras foram analisadas nos meses 0,4 e 9 de armazenamento. Os resultados foram expressos em \% do conteúdo total dos ácidos graxos.

\subsection{6 pH}

$\mathrm{O} \mathrm{pH}$ foi determinado com um potenciômetro Digimed - DMPH-2 em uma mistura de partes iguais de carne e de água recém-destilada, após homogeneização da carne em um multiprocessador de alimentos da marca Arno, método $n^{\circ}$ 950.48, segundo AOAC (1995), nos meses 0, 1, 2, 4, 7 e 9 de armazenamento.

\subsubsection{Cor}

A cor foi determinada através de quatro leituras na parte ventral das amostras inteiras através do colorímetro Chroma meter - 200b da marca MINOLTA, pelo sistema $L^{*}$ (luminosidade), $a^{*}$, croma variando do vermelho $\left(^{+}\right)$ ao verde (-) e $b^{*}$, croma variando do amarelo (+) ao azul (-), nos meses $0,1,2$, 4, 7 e 9 de armazenamento.

\subsubsection{TBARS (Thiobarbituric acid reactive substances)}

Foi determinado em triplicata segundo a metodologia de Tarladgis et al. (1960), nos meses 0, 1, 2, 4, 6 e 9 de armazenamento. O padrão utilizado nesta reação é o 1,1',3,3" tetraetoxipropano (TEP), cuja hidrólise ácida gera malonaldeído na proporção de $1 \mathrm{~mol}: 1 \mathrm{~mol}$. Torna-se possível, desta forma, expressar os resultados em termos de "valor de TBARS" que é definido como mg de malonaldeído/1000g de amostra.

As sobrecoxas de frango foram picadas e, posteriormente, amostras de 
$100 \mathrm{~g}$ foram homogeneizadas em um multiprocessador de alimentos da marca Arno com $10 \mathrm{~mL}$ de BHT em etanol (na concentração de $1 \mathrm{mg} / \mathrm{mL}$ ), para prevenir a oxidação durante o preparo. Após este procedimento foram pesadas $10 \mathrm{~g}$ em duplicata em balões volumétricos de $250 \mathrm{~mL}$ e, em seguida, adicionados de $96,5 \mathrm{~mL}$ de água destilada, $2,5 \mathrm{~mL}$ de ácido clorídrico, $1 \mathrm{~mL}$ de BHT em etanol (1 mg/mL), 5 gotas de antiespumante e 4 contas de vidro, para a destilação.

O líquido destilado, cerca de $50 \mathrm{~mL}$, foi recolhido em um beaker de $50 \mathrm{~mL}$. Foram pipetados $3 \mathrm{~mL}$ deste destilado em um tubo de ensaio com tampa e adicionados $3 \mathrm{~mL}$ da solução de TBA. Em seguida, as amostras foram colocadas em banho-maria a $100^{\circ} \mathrm{C}$ por 30 minutos, seguido das leituras em espectrofotômetro em $532 \mathrm{~nm}$.

Para a curva padrão, amostras da sobrecoxa foram preparadas da mesma forma citada, sendo que foram adicionadas quantidades diferentes $(0,0$; 0,5; 1,0; 2,0; 5,0; 8,0 e 10,0 mL) de 1,1',3,3" Tetratoxipropano (TEP), $2,5 \mathrm{~mL}$ de ácido clorídrico, 1,0 mL de BHT em etanol (1 mg/mL) e 96,5; 96,0; 95,5; 94,5; 91,$5 ; 88,5 ; 86,5 \mathrm{~mL}$ de água destilada, respectivamente, conforme as quantidades de TEP utilizadas. Foram preparados também, balões sem amostra com as mesmas concentrações de TEP, ácido clorídrico e BHT em etanol ( $1 \mathrm{mg} / \mathrm{mL})$, e 106,$5 ; 106,0 ; 105,5 ; 104,5 ; 101,5 ; 98,5$ e $96,5 \mathrm{~mL}$ de água destilada, como controle.

O teor de malonaldeído na amostra foi calculado utilizando-se a equação da curva padrão normal e dividindo-se o valor obtido pela porcentagem de recuperação, ou diretamente, utilizando-se a equação da curva padrão com adição de amostra.

Fórmula para cálculo utilizando a equação linear da curva com padrões destilados sozinhos:

$\mathrm{mg}$ de malonaldeído $/ 1000 \mathrm{~g}=\underline{\mu g}$ de malonaldeído $/ \mathrm{mL} \times 50 \times 1000 \times 100$

$A \times B \times 1000$

Fórmula para cálculo utilizando a equação linear da curva com padrões 
destilados com amostras:

$\mathrm{mg}$ de malonaldeído $/ 1000 \mathrm{~g}=\underline{\mu \mathrm{g} \text { de malonaldeído } \times 50 \times 1000}$

A $\times 1000$

em que:

A: peso da amostra

B: \% de recuperação do padrão

\subsubsection{Análise Sensorial}

Para a análise sensorial das sobrecoxas de frango, primeiramente foi realizado um treinamento em Análise Descritiva Quantitativa, para que os provadores tomassem contato com um produto rançado e um não rançado, analisando o atributo sensorial de odor. Para isso, foi utilizado óleo de soja refinado fresco, adquirido no comércio local no dia do treinamento e um óleo de soja oxidado, obtido no Laboratório de Óleos e Gorduras. Foi então explicado aos provadores o que era ranço, e em seguida, ofereceram-se os óleos fresco e oxidado a uma temperatura de $30^{\circ} \mathrm{C}$, para que os mesmos pudessem diferenciar os dois tipos de odor.

A equipe de provadores foi constituída de funcionários e alunos do Departamento de Agroindústria, Alimentos e Nutrição, ESALQ/USP.

Após o treinamento, foram escolhidos 10 provadores, para quantificar a intensidade do atributo odor, utilizando-se uma escala estruturada de 0 a $9 \mathrm{~cm}$ (Stone et al., 1974), ancorada nas extremidades com os termos "pouco rançado e muito rançado" (Figura 2). Este tipo de análise é conhecido como método descritivo, classificado como avaliação de atributos - escalas, que determinam a intensidade de cada atributo sensorial presente na amostra. Estas escalas permitem avaliar a intensidade da sensação e a direção das diferenças entre as amostras. Através delas é possível descobrir o quanto as amostras diferem entre si, e qual a amostra que apresenta maior intensidade do atributo sensorial que está sendo avaliado, exigindo assim um maior treinamento e habilidade do provador (Dutcosky, 1996). As sobrecoxas envoltas em papel alumínio foram 
aquecidas em uma chapa, até que chegassem a uma temperatura de $80^{\circ} \mathrm{C}$, identificadas com códigos, foram oferecidas aos provadores, para análise do atributo odor.

Nome:

Data:

Obrigado por participar da nossa pesquisa com SOBRECOXA DE FRANGO. Indique na escala abaixo o quanto a sobrecoxa está muito ou pouco rançada, quanto ao ODOR.

pouco rançado muito rançado

Comentários:

Figura 2 - Modelo da ficha utilizada na análise sensorial em que: pouco rançado $=0$ muito rançado $=9$

\subsubsection{Análise Estatística}

O ensaio de armazenamento foi realizado em um delineamento inteiramente casualizado no esquema fatorial $6 \times 6$ (6 tratamentos $\times 6$ tempos). A análise estatística dos dados foi realizada no programa SAS - Statistical Analysis System (SAS Institute, 1996) utilizando o procedimento GLM. Foi feita a análise de variância para as variáveis $\mathrm{pH}$, cor, TBA e como a interação tempo $x$ tratamento foi significativa, foi feito desdobramento da análise com aplicação do Teste de Tukey. 


\section{RESULTADOS E DISCUSSÃO}

\subsection{Análises das fontes lipídicas da dieta}

As fontes lipídicas da dieta, OS, FR e OS25AC75 apresentaram boa qualidade oxidativa inicial (Tabela 8), confirmada pela ausência de peróxidos e baixa acidez. A acidez apresentou-se elevada (0,4366; 0,3600 e 0,2866 mg $\mathrm{KOH} / \mathrm{g}$ ), como era de se esperar, nas amostras de óleo ácido de soja e nas misturas OS50AC50 e OS50FR50, devido à presença de maiores quantidades de ácidos graxos livres neste produto.

A absortividade, a qual efetivamente caracteriza o estado oxidativo do óleo, teve um valor máximo de 0,2802 em $232 \mathrm{~nm}$ e 0,1601 em $270 \mathrm{~nm}$ para o óleo ácido de soja, os quais são bastante baixos, indicando pequena quantidade de compostos primários e secundários da oxidação, corroborando a inexistência de peróxidos (Tabela 8).

Bou et al. (2001) consideraram que óleo de girassol apresentava-se oxidado a partir de absortividades de 4,40 e 0,83 em 232nm e 270 nm, respectivamente. Já Racanicci (2004) ao promover a deterioração oxidativa em óleo de vísceras de aves, considerou os valores de 11,33 e 2,31 para as absortividades em 232 e $270 \mathrm{~nm}$, respectivamente. 
Tabela 8. Valores médios do índice de peróxido, acidez e absortividade, das diferentes fontes lipídicas e suas misturas adicionadas à dieta dos animais.

\begin{tabular}{|c|c|c|c|c|}
\hline Tratamentos & $\begin{array}{c}\text { Índice de peróxido } \\
\text { meq } \mathrm{O}_{2} / \mathrm{kg}\end{array}$ & Acidez $\mathrm{mg} \mathrm{KOH} / \mathrm{g}$ & E $232 \mathrm{~nm}$ & E $270 \mathrm{~nm}$ \\
\hline OS & 0 & $0,0200^{d}$ & $0,2000^{f}$ & $0,1510^{d}$ \\
\hline FR & 0 & $0,0266^{d}$ & $0,2082^{e}$ & $0,1503^{\mathrm{e}}$ \\
\hline$A C$ & 0 & $0,4366^{a}$ & $0,2802^{a}$ & $0,1601^{a}$ \\
\hline OS25AC75 & 0 & $0,0300^{c}$ & $0,2152^{d}$ & $0,1507^{d e}$ \\
\hline OS50AC75 & 0 & $0,3600^{b}$ & $0,2423^{c}$ & $0,1536^{c}$ \\
\hline OS50FR50 & 0 & $0,2866^{d}$ & $0,2503^{b}$ & $0,1572^{b}$ \\
\hline CV \% & - & 6,67 & 0,11 & 0,15 \\
\hline
\end{tabular}

a - letras minúsculas diferentes na mesma coluna diferem estatisticamente entre si $(P<0,05)$ pelo teste Tukey.

CV \%: Coeficiente de variação

Legenda: OS: óleo de soja, FR: óleo de vísceras de aves, AC: óleo ácido de soja, OS25AC75: mistura de $25 \%$ de óleo de soja e $75 \%$ óleo ácido de soja, OS50AC50: mistura de 50\% de óleo de soja e $50 \%$ de óleo ácido de soja, OS50FR50: mistura de 50\% de óleo de soja e $50 \%$ de óleo de vísceras de aves.

$\mathrm{Na}$ Tabela 9 observa-se a composição de ácidos graxos das diferentes fontes lipídicas utilizadas neste estudo. A comparação entre o óleo de soja e o óleo ácido de soja possibilita a visualização do efeito de oxidação lipídica sobre o óleo ácido e as misturas em que este foi utilizado, havendo uma significativa perda de ácido linoléico (C18:2) e linolênico (C18:3), ou seja, os ácidos graxos insaturados, principais componentes afetados, corroborando os resultados obtidos nas análises de acidez e absortividade, os quais foram superiores no óleo ácido de soja. Como os ácidos graxos são quantificados em porcentagem do total da área dos picos, a introdução do oxigênio na molécula insaturada pode provocar um comprometimento das duplas ligações, e, consequentemente, as moléculas mais insaturadas deixam de ser identificadas 
como tal, fazendo com que haja um incremento artificial das espécies menos insaturadas, como revelado na Tabela 9. Consequentemente, a proporção de ácidos graxos saturados e insaturados nas duas amostras em questão, apresentaram modificações, sendo a quantidade de insaturados bastante reduzida e a de saturados aumentada no óleo ácido de soja. Racanicci (2004) comparando o perfil de ácidos graxos do óleo de vísceras de aves oxidado com o do óleo de vísceras fresco, verificou que ocorreu uma pequena queda no teor de ácidos graxos insaturados, mais especificamente no ácido linoléico no óleo oxidado.

Tabela 9. Perfil de ácidos graxos das fontes lipídicas utilizadas na produção das rações experimentais $(n=1)$

\begin{tabular}{lcccccc}
\hline Ácidos Graxos (\%) & SO & FR & AC & SO25/ & SO50/ & S050/ \\
& & & & AC75 & AC50 & FR50 \\
\hline Ác. Palmítico (C16:0) & 14,8 & 24,74 & 25,66 & 22,25 & 19,77 & 20,23 \\
Ác. Palmitoléico (C16:1) & 3,11 & 3,90 & 6,66 & 3,70 & 3,50 & 4,88 \\
Ác. Esteárico (C18:0) & 0,31 & 1,56 & 7,28 & 1,25 & 0,93 & 3,79 \\
Ác. Oléico (C18:1) & 23,79 & 31,40 & 44,53 & 29,50 & 27,60 & 34,15 \\
Ác. Linoléico (C18:2) & 51,36 & 15,14 & 5,87 & 13,15 & 25,88 & 26,37 \\
Ác. Linolênico (C18:3) & 5,82 & 1,51 & 1,38 & 12,81 & 10,48 & 5,84 \\
Ac. Araquídico (C20:0) & 0,22 & 13,80 & 4,99 & 10,40 & 7,00 & 2,61 \\
Total Saturados & 15,33 & 40,10 & 37,94 & 33,90 & 27,70 & 26,63 \\
Total Insaturados & 81,52 & 51,95 & 58,44 & 59,16 & 67,46 & 71,24
\end{tabular}

Legenda: OS: óleo de soja, FR: óleo de vísceras de aves, AC: óleo ácido de soja, OS25AC75: mistura de $25 \%$ de óleo de soja e $75 \%$ óleo ácido de soja, OS50AC50: mistura de 50\% de óleo de soja e $50 \%$ de óleo ácido de soja, OS50FR50: mistura de 50\% de óleo de soja e 50\% de óleo de vísceras de aves. 


\subsection{Composição Centesimal}

A carne de sobrecoxas dos frangos alimentados com dietas adicionadas das diferentes fontes lipídicas apresentou em média de 68 a 70\% de umidade, 16,33 a $18,19 \%$ de proteína bruta, $11 \%$ de lipídios, $0,80 \%$ de cinza e 1,2\% de carboidratos (Tabela 10). Estes resultados são semelhantes ao 19,7\% encontrado na literatura para proteína bruta segundo Franco (2001) e 18\%, segundo a Tabela Brasileira de Composição de Alimentos (2004), e para umidade $(70 \%)$ e cinza $(0,80 \%)$ obtidos por Racanicci (2004). Já os valores encontrados para o teor de gordura foram superiores aos da literatura, $3,10 \%$ de óleo, segundo Franco (2001) e 3,91\%, segundo a tabela de referência de nutrientes adotada pelo Departamento de Agricultura dos Estados Unidos, USDA (Estados Unidos, 2004). Já Racanicci (2004), trabalhando com frangos com dieta de óleos vísceras oxidada ou não, encontrou valores mais próximos dos deste estudo, isto é, $12,47 \%$. Estas variações entre os resultados deste estudo e a literatura podem ser consideradas normais e decorrentes de diferenças entre linhagens, idade de abate e alimentação.

Tabela 10. Composição centesimal das sobrecoxas de frangos alimentados as diferentes fontes lipídicas (\%) $(n=3)$

\begin{tabular}{lccccc}
\hline Tratamentos & Umidade & Gordura* $^{*}$ & $\begin{array}{c}\text { Proteína } \\
\text { Bruta* }^{*}\end{array}$ & Cinza* $^{*}$ & $\begin{array}{c}\text { Carboidratos } \\
*\end{array}$ \\
\hline OS & $70,17^{\mathrm{a}}$ & $11,00^{\mathrm{c}}$ & $16,76^{\mathrm{c}}$ & $0,81^{\mathrm{b}}$ & 1,27 \\
FR & $68,35^{\mathrm{c}}$ & $11,39^{\mathrm{b}}$ & $18,19^{\mathrm{a}}$ & $0,81^{\mathrm{b}}$ & 1,24 \\
AC & $70,26^{\mathrm{a}}$ & $11,38^{\mathrm{b}}$ & $16,33^{\mathrm{d}}$ & $0,82^{\mathrm{b}}$ & 1,20 \\
OS25AC75 & $68,07^{\mathrm{d}}$ & $11,72^{\mathrm{a}}$ & $18,17^{\mathrm{a}}$ & $0,87^{\mathrm{a}}$ & 1,15 \\
OS50AC50 & $69,83^{\mathrm{b}}$ & $11,37^{\mathrm{b}}$ & $16,81^{\mathrm{c}}$ & $0,80^{\mathrm{b}}$ & 1,17 \\
OS50FR50 & $69,79^{\mathrm{b}}$ & $11,09^{\mathrm{c}}$ & $17,11^{\mathrm{b}}$ & $0,81^{\mathrm{b}}$ & 1,19 \\
CV \% & $0,06^{\mathrm{b}}$ & $0,54^{\mathrm{a}}$ & 0,20 & 2,38 & 4,80
\end{tabular}

a- letras minúsculas diferentes na mesma coluna diferem estatisticamente entre si $(P<0,05)$ pelo teste Tukey; * valores calculados em base seca. 
CV \%: Coeficiente de variação

Legenda: OS: óleo de soja, FR: óleo de vísceras de aves, AC: óleo ácido de soja, OS25AC75: mistura de $25 \%$ de óleo de soja e $75 \%$ óleo ácido de soja, OS50AC50: mistura de $50 \%$ de óleo de soja e $50 \%$ de óleo ácido de soja, OS50FR50: mistura de 50\% de óleo de soja e 50\% de óleo de vísceras de aves.

\subsection{Perfil de ácidos graxos da carne de sobrecoxas}

O perfil de ácidos graxos das sobrecoxas de frangos alimentados com dietas adicionadas de diferentes fontes lipídicas foi determinado nos meses 0,4 e 9 de armazenamento sob congelamento.

As carnes das sobrecoxas dos animais alimentados com dietas adicionadas de óleo de soja e frango apresentaram quantidades de ácidos graxos linoléico e linolênico superiores aos da carne de frangos alimentados com dietas adicionadas do óleo ácido (Tabelas 11, 12 e 13). Novamente corroborando os resultados de acidez e absortividade, os quais foram superiores para o óleo ácido de soja, indica que a oxidação interfere no grau de insaturação das gorduras, agindo sobre as espécies mais insaturadas.

O perfil de ácidos graxos encontrado nas frações lipídicas das sobrecoxas pouca diferença apresentou do normalmente verificado para esse músculo. A maior proporção dos ácidos graxos está representada pelos de cadeias de 16 e 18 carbonos. Racanicci (2004), também trabalhando com sobrecoxas de frango, encontrou um teor de ácido oléico $(39,47 \%)$ superior ao verificado nas amostras de carnes de animais também alimentados com óleo de vísceras deste estudo (33,06\%), o que talvez possa ser explicado pela qualidade oxidativa superior das fontes lipídicas empregadas neste estudo. Pode-se dizer que o tempo de armazenamento muito pouco afetou a composição, como se pode verificar através das Tabelas 11, 12 e 13. 
Tabela 11. Perfil de ácidos graxos das sobrecoxas de frangos alimentados com as diferentes fontes lipídicas no mês 0 de armazenamento $(n=1)$

\begin{tabular}{lcccccc}
\hline Ácidos Graxos (\%) & SO & FR & AC & SO25/ & SO50/ & SO50/ \\
& & & & AC75 & AC50 & FR50 \\
\hline Ác. Mirístico (C14:0) & 0,55 & 0,55 & 0,73 & 0,55 & 0,57 & 0,50 \\
Ác. Palmítico (C16:0) & 24,04 & 23,38 & 26,43 & 25,07 & 21,98 & 21,63 \\
Ác. Palmitoléico (C16:1) & 4,77 & 3,82 & 6,88 & 2,87 & 2,98 & 2,90 \\
Ác. Esteárico (C18:0) & 6,25 & 6,33 & 6,45 & 5,79 & 6,03 & 6,77 \\
Ác. Oléico (C18:1) & 32,97 & 33,06 & 40,84 & 30,73 & 32,0 & 32,48 \\
Ác. Linoléico (C18:2) & 29,27 & 30,86 & 17,89 & 32,99 & 32,35 & 33,65 \\
Ac. Linolênico (C18:3) & 2,12 & 1,74 & 0,73 & 1,98 & 2,06 & 2,04 \\
Total Saturados & 30,85 & 30,28 & 33,63 & 31,42 & 28,59 & 28,91 \\
Total Insaturados & 69,15 & 69,50 & 66,36 & 68,57 & 69,40 & 71,08 \\
\hline
\end{tabular}

Legenda: OS: óleo de soja, FR: óleo de vísceras de aves, AC: óleo ácido de soja, OS25AC75: mistura de $25 \%$ de óleo de soja e $75 \%$ óleo ácido de soja, OS50AC50: mistura de $50 \%$ de óleo de soja e $50 \%$ de óleo ácido de soja, OS50FR50: mistura de $50 \%$ de óleo de soja e $50 \%$ de óleo de vísceras de aves. 
Tabela 12. Perfil de ácidos graxos das sobrecoxas de frangos alimentados com as diferentes fontes lipídicas no mês 4 de armazenamento $(n=1)$

\begin{tabular}{lllllll}
\hline Ácidos Graxos (\%) SO & FR & AC & SO25/ SO50/ SO50/
\end{tabular}

AC75 AC50 FR50

\begin{tabular}{lllllll}
\hline Ác. Mirístico (C14:0) & 0,57 & 0,61 & 0,69 & 0,54 & 0,72 & 0,58
\end{tabular}

$\begin{array}{lllll}\text { Ác. Palmítico (C16:0) } \quad 25,32 & 23,70 & 26,82 & 22,16 & 25,87\end{array}$

$\begin{array}{llllll}\text { Ác. Palmitoléico (C16:1) } \quad 5,01 & 3,79 & 6,55 & 3,02 & 6,20 & 3,03\end{array}$

Ác. Esteárico (C18:0) $\quad 6,02 \quad 6,35 \quad 6,97 \quad 6,66 \quad 4,59 \quad 6,65$

Ác. Oléico (C18:1) $\quad 32,16 \quad 32,97 \quad 41,33 \quad 31,79 \quad 37,15 \quad 31,72$

Ác. Linoléico (C18:2) $\quad 28,78 \quad 30,85 \quad 16,95 \quad 33,75 \quad 23,98 \quad 33,46$

$\begin{array}{lllllll}\text { Ac. Linolênico (C18:3) } \quad 2,11 & 1,70 & 0,65 & 2,04 & 1,46 & 2,05\end{array}$

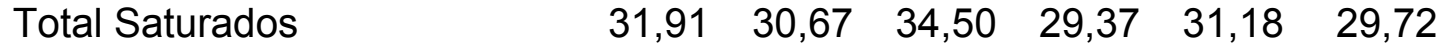

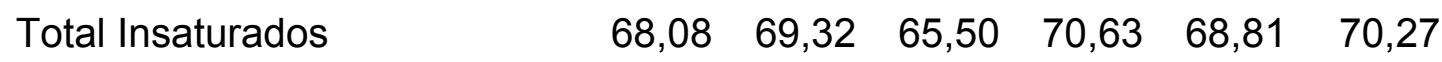

Legenda: OS: óleo de soja, FR: óleo de vísceras de aves, AC: óleo ácido de soja, OS25AC75: mistura de $25 \%$ de óleo de soja e $75 \%$ óleo ácido de soja, OS50AC50: mistura de 50\% de óleo de soja e $50 \%$ de óleo ácido de soja, OS50FR50: mistura de 50\% de óleo de soja e 50\% de óleo de vísceras de aves. 
Tabela 13. Perfil de ácidos graxos das sobrecoxas de frangos alimentados com as diferentes fontes lipídicas no mês 9 de armazenamento $(n=1)$

\begin{tabular}{lcccccc}
\hline Ácidos Graxos (\%) & SO & FR & AC & SO25/ & SO50/ & SO50/ \\
& & & & AC75 & AC50 & FR50 \\
\hline Ác. Mirístico (C14:0) & 0,57 & 0,58 & 0,72 & 0,59 & 0,58 & 0,65 \\
Ác. Palmítico (C16:0) & 26,06 & 24,75 & 27,31 & 23,37 & 25,42 & 23,84 \\
Ác. Palmitoléico (C16:1) & 5,08 & 4,31 & 6,77 & 6,47 & 5,98 & 3,26 \\
Ác. Esteárico (C18:0) & 5,98 & 6,19 & 6,90 & 3,20 & 6,00 & 6,49 \\
Ác. Oléico (C18:1) & 31,86 & 31,91 & 40,77 & 30,98 & 36,73 & 30,83 \\
Ác. Linoléico (C18:2) & 28,38 & 30,56 & 16,84 & 33,32 & 23,78 & 32,93 \\
Ac. Linolênico (C18:3) & 2,02 & 1,67 & 0,67 & 2,03 & 1,48 & 1,97 \\
Total Saturados & 32,63 & 31,53 & 34,93 & 30,44 & 32,00 & 30,99 \\
Total Insaturados & 67,36 & 68,46 & 65,06 & 69,55 & 67,99 & 69,00 \\
\hline
\end{tabular}

Legenda: OS: óleo de soja, FR: óleo de vísceras de aves, AC: óleo ácido de soja, OS25AC75: mistura de $25 \%$ de óleo de soja e $75 \%$ óleo ácido de soja, OS50AC50: mistura de 50\% de óleo de soja e $50 \%$ de óleo ácido de soja, OS50FR50: mistura de 50\% de óleo de soja e $50 \%$ de óleo de vísceras de aves.

\section{$4.4 \mathrm{pH}$}

O valor de $\mathrm{pH}$ é uma medida muito importante para a indústria de processamento de carne de aves. Um valor abaixo de 5,7 logo após o abate é um dos fatores que acarreta o desenvolvimento de carnes com características PSE (pale, soft e exudative). Isto porque ocorre o comprometimento das suas propriedades funcionais, devido à desnaturação das proteínas miofibrilares e sarcoplasmáticas, ocasionando problemas em produtos processados de aves, reduzindo o rendimento dos produtos com conseqüentes perdas econômicas (Olivo e Shimokomaki, 2001).

Neste estudo os valores de $\mathrm{pH}$ da sobrecoxa de frango durante os 9 meses de armazenamento sob congelamento variaram de 5,88 a 6,39 (Tabela 14) e não foram influenciados pelos tratamentos ou pelo tempo de 
armazenamento. Estes valores encontram-se dentro da faixa citada pela literatura. Beraquet (2000) verificou que carne de sobrecoxa desossada manualmente apresentou um $\mathrm{pH}$ de aproximadamente 5,8 a 6,2. Kondaiah e Panda (1987) mediram o pH da carne de peito e coxa de frangos e encontraram valores de 5,94 e 6,10, respectivamente. Racanicci (2004) obteve um pH de 6,17 para sobrecoxa de frangos, alimentados com dietas adicionadas de óleo de vísceras de frango fresco e oxidado.

Tabela 14. Valores médios de pH para carne de sobrecoxa de frango, alimentados com dietas adicionadas de diferentes fontes lipídicas e suas misturas $(n=3)$

\begin{tabular}{|c|c|c|c|c|c|c|}
\hline \multirow[t]{2}{*}{ Tratamentos } & \multicolumn{6}{|c|}{ Período de Armazenamento (Meses) } \\
\hline & 0 & 1 & 2 & 4 & 6 & 9 \\
\hline OS & $6,34^{a}$ & $6,30^{a}$ & $6,10^{\mathrm{ab}}$ & $5,90^{b}$ & $6,12^{a}$ & $6,20^{a}$ \\
\hline FR & $6,21^{a b}$ & $6,38^{a}$ & $5,88^{b}$ & $5,88^{b}$ & $6,00^{a b}$ & $6,22^{a b}$ \\
\hline$A C$ & $6,07^{a}$ & $6,17^{a}$ & $5,90^{a}$ & $6,20^{a}$ & $6,11^{a}$ & $6,19^{a}$ \\
\hline OS25AC75 & $6,22^{a}$ & $6,12^{a}$ & $6,15^{a}$ & $5,95^{a}$ & $6,23^{a}$ & $6,30^{a}$ \\
\hline OS50AC50 & $6,33^{a}$ & $6,21^{a}$ & $6,16^{a}$ & $6,16^{a}$ & $6,22^{a}$ & $6,24^{a}$ \\
\hline OS50FR50 & $6,18^{a}$ & $6,05^{a}$ & $6,15^{a}$ & $6,04^{a}$ & $6,13^{a}$ & $6,24^{a}$ \\
\hline
\end{tabular}

a - letras minúsculas diferentes na mesma linha diferem estatisticamente entre si $(P<0,05)$ Coeficiente de Variação: 1,95\%

Legenda: OS: óleo de soja, FR: óleo de vísceras de aves, AC: óleo ácido de soja, OS25AC75: mistura de $25 \%$ de óleo de soja e $75 \%$ óleo ácido de soja, OS50AC50: mistura de 50\% de óleo de soja e 50\% de óleo ácido de soja, OS50FR50: mistura de 50\% de óleo de soja e 50\% de óleo de vísceras de aves. 


\subsection{Cor}

A cor é considerada um importante parâmetro de qualidade para produtos alimentícios, principalmente para produtos cárneos, já que influencia a aceitabilidade do produto. Os consumidores normalmente rejeitam produtos em que a cor é diferente da esperada, portanto esta variável pode ser utilizada para determinar o valor comercial do alimento (Qiao et al., 2001).

Defeitos de cor em carne de frango, como PSE (pale, soft e exudative), tem sido um problema para a indústria processadora de alimentos a partir da carne de aves frescas ou cozidas.

Jensen et al. (1998) afirmaram que a descoloração das carnes frescas está relacionada com a oxidação de pigmentos e com a eficiência dos sistemas enzimáticos redutores da metamioglobina.

Alguns autores (Qiao et al., 2000) demonstraram uma relação entre a cor da carne fresca com o pH, ambos associados à propriedades funcionais da carne. Segundo Qiao et al. (2001), o valor de $L^{*}$ (luminosidade), dentre as demais medidas de cor ( $a^{*}$ e $\left.b^{*}\right)$, é o que tem uma correlação maior com o PSE. Quanto mais alta a luminosidade, mais pálida encontra-se a carne. Peitos com $L^{*}$ maior que 49 são classificados como carne PSE.

Os valores de $L^{*}$ do início do experimento encontraram-se dentro da faixa normalmente aceita para sobrecoxas (42,51 a 44,61), apesar de diferirem significativamente entre si nos três primeiros meses de armazenamento (Tabela 15). O tempo de armazenamento teve influência sobre a luminosidade da carne. Como era de se esperar, no último mês do experimento, os valores de $L^{*}$ foram mais altos (Tabela 15), uma vez que a carne pode sofrer desidratação durante o armazenamento. Interpolando estes valores $L^{*}, a^{*} e b^{*}$ no diagrama de cores, verifica-se que, nos primeiros meses de armazenamento (Tabelas 15, 16 e 17) a carne apresentou-se mais "vermelha brilhante" ( $\left.a^{*}\right)$, o que é normal já que as sobrecoxas contém um teor de mioglobina maior do que outras partes do frango, como o peito, por exemplo. Verificou-se também que com o tempo de armazenamento, a carne foi se tornando menos brilhante, isto é, ela adquiriu 
uma cor mais pálida indicada pelos maiores valores do $L^{*}$ no sexto e nono mês de armazenamento (Tabela 15).

Tabela 15. Valores médios de L* (luminosidade) para as sobrecoxas de frango dos diferentes tratamentos $(n=3)$

\begin{tabular}{|c|c|c|c|c|c|c|}
\hline \multirow[t]{2}{*}{ Tratamentos } & \multicolumn{6}{|c|}{ Período de Armazenamento (Meses) } \\
\hline & 0 & 1 & 2 & 4 & 6 & 9 \\
\hline OS & $43,82^{\text {et } A B C}$ & $43,40^{\Upsilon A B}$ & $46,37^{\mathrm{bcd} A}$ & $44,97^{\mathrm{de}}$ & $45,25^{\mathrm{cdBC}}$ & $48,20^{a}$ \\
\hline FR & $44,61^{\operatorname{def} \mathrm{A}}$ & $44,17^{\text {ef } A B}$ & $43,70^{f D}$ & $44,95^{\text {cdef }}$ & $46,66^{\mathrm{bA}}$ & $48,40^{a}$ \\
\hline$A C$ & $42,51^{\mathrm{fD}}$ & $42,29^{\text {ef } D}$ & $44,40^{\mathrm{d} C D}$ & $44,90^{\text {cd }}$ & $45,73^{\mathrm{bcdBC}}$ & $48,00^{a}$ \\
\hline OS25AC75 & $42,58^{\mathrm{fBCD}}$ & $42,87^{\text {ef } C D}$ & $45,66^{\mathrm{cdABC}}$ & $45,62^{d}$ & $45,95^{\mathrm{bcdABC}}$ & $47,95^{a}$ \\
\hline OS50AC50 & $44,01^{\mathrm{eA}}$ & $44,42^{\text {ef A }}$ & $45,61^{\mathrm{dABC}}$ & $45,67^{c d}$ & $46,34^{\mathrm{bcdABC}}$ & $48,16^{a}$ \\
\hline OS50FR50 & $42,58^{\mathrm{fBCD}}$ & $43,35^{\mathrm{efBCD}}$ & $44,51^{\text {deBCD }}$ & $45,16^{\mathrm{a}}$ & $44,95^{\mathrm{cC}}$ & $48,21^{\mathrm{a}}$ \\
\hline
\end{tabular}

a - letras minúsculas diferentes na mesma linha diferem estatisticamente entre si $(\mathrm{P}<0,05)$

A - letras maiúsculas diferentes na mesma coluna diferem estatisticamente entre si $(P<0,05)$

Coeficiente de Variação: 0,97\%

Legenda: OS: óleo de soja, FR: óleo de vísceras de aves, AC: óleo ácido de soja, OS25AC75: mistura de $25 \%$ de óleo de soja e $75 \%$ óleo ácido de soja, OS50AC50: mistura de $50 \%$ de óleo de soja e 50\% de óleo ácido de soja, OS50FR50: mistura de 50\% de óleo de soja e 50\% de óleo de vísceras de aves.

Tabela 16. Valores médios de $a^{*}$ (croma variando do vermelho ao verde) para as sobrecoxas de frango dos diferentes tratamentos $(n=3)$

\begin{tabular}{lcccccc}
\hline Tratamentos & \multicolumn{5}{c}{ Período de Armazenamento (Meses) } \\
& 0 & 1 & 2 & 4 & 6 & 9 \\
\hline OS & $12,46^{\mathrm{dAB}}$ & $12,70^{\mathrm{CdA}}$ & $14,14^{\mathrm{ab}}$ & $14,58^{\mathrm{a}}$ & $14,44^{\mathrm{aB}}$ & $12,90^{\mathrm{bcd}}$ \\
FR & $11,24^{\mathrm{dBC}}$ & $12,70^{\mathrm{CA}}$ & $15,54^{\mathrm{aA}}$ & $15,36^{\mathrm{a}}$ & $16,47^{\mathrm{aA}}$ & $13,55^{\mathrm{bc}}$ \\
AC & $11,19^{\mathrm{dC}}$ & $12,40^{\mathrm{cdA}}$ & $15,49^{\mathrm{aA}}$ & $15,64^{\mathrm{a}}$ & $15,98^{\mathrm{aA}}$ & $13,27^{\mathrm{bc}}$ \\
OS25AC75 & $12,47^{\mathrm{dAB}}$ & $12,88^{\mathrm{bcdA}}$ & $15,60^{\mathrm{aA}}$ & $15,53^{\mathrm{a}}$ & $16,20^{\mathrm{aA}}$ & $12,58^{\mathrm{cd}}$ \\
OS50AC50 & $12,98^{\mathrm{dA}}$ & $12,84^{\mathrm{dA}}$ & $15,33^{\mathrm{aAB}}$ & $15,83^{\mathrm{a}}$ & $15,43^{\mathrm{aAB}}$ & $12,96^{\mathrm{cd}}$ \\
OS50FR50 & $12,50^{\mathrm{dA}}$ & $12,52^{\mathrm{CdA}}$ & $15,40^{\mathrm{aA}}$ & $15,79^{\mathrm{a}}$ & $15,70^{\mathrm{aA}}$ & $12,58^{\mathrm{bcd}}$ \\
\hline
\end{tabular}

a - letras minúsculas diferentes na mesma linha diferem estatisticamente entre si $(\mathrm{P}<0,05)$

A - letras maiúsculas diferentes na mesma coluna diferem estatisticamente entre si $(P<0,05)$ 
Coeficiente de Variação: $2,78 \%$

Legenda: OS: óleo de soja, FR: óleo de vísceras de aves, AC: óleo ácido de soja, OS25AC75: mistura de $25 \%$ de óleo de soja e $75 \%$ óleo ácido de soja, OS50AC50: mistura de $50 \%$ de óleo de soja e 50\% de óleo ácido de soja, OS50FR50: mistura de 50\% de óleo de soja e 50\% de óleo de vísceras de aves.

Tabela 17. Valores médios de $b^{*}$ (croma variando do amarelo ao azul) para as sobrecoxas de frango dos diferentes tratamentos $(n=3)$

\begin{tabular}{lcccccc}
\hline Tratamentos & \multicolumn{5}{c}{ Período de Armazenamento (Meses) } \\
& 0 & 1 & 2 & 4 & 6 & 9 \\
\hline OS & $10,19^{\mathrm{d}}$ & $10,30^{\mathrm{cd}}$ & $11,20^{\mathrm{bcdABCD}}$ & $12,83^{\mathrm{aA}}$ & $12,45^{\mathrm{abA}}$ & $11,73^{\mathrm{ab}}$ \\
FR & $9,39^{\mathrm{d}}$ & $9,45^{\mathrm{cd}}$ & $9,81^{\mathrm{bcdE}}$ & $12,80 \mathrm{aA}$ & $13,18^{\mathrm{aA}}$ & $12,43^{\mathrm{a}}$ \\
AC & $9,53^{\mathrm{d}}$ & $9,98^{\mathrm{cd}}$ & $10,46^{\mathrm{bcdBCDE}}$ & $11,06^{\mathrm{abcB}}$ & $11,31^{\mathrm{abC}}$ & $12,15^{\mathrm{a}}$ \\
OS25AC75 & $10,10^{\mathrm{d}}$ & $10,26^{\mathrm{cd}}$ & $11,87^{\mathrm{bA}}$ & $12,42^{\mathrm{abA}}$ & $13,20^{\mathrm{aA}}$ & $11,93^{\mathrm{ab}}$ \\
OS50AC50 & $9,88^{\mathrm{cd}}$ & $9,87^{\mathrm{d}}$ & $10,46^{\mathrm{bcdCDE}}$ & $12,58^{\mathrm{aA}}$ & $13,27^{\mathrm{aA}}$ & $12,13^{\mathrm{a}}$ \\
OS50FR50 & $10,05^{\mathrm{d}}$ & $10,40^{\mathrm{cd}}$ & $10,41^{\mathrm{bcdDE}}$ & $10,61^{\mathrm{abcdC}}$ & $10,64^{\mathrm{abcdD}}$ & $11,80^{\mathrm{a}}$ \\
\hline
\end{tabular}

a - letras minúsculas diferentes na mesma linha diferem estatisticamente entre si $(P<0,05)$

A - letras maiúsculas diferentes na mesma coluna diferem estatisticamente entre si $(P<0,05)$

Coeficiente de Variação: 3,56\%

Legenda: OS: óleo de soja, FR: óleo de vísceras de aves, AC: óleo ácido de soja, OS25AC75: mistura de $25 \%$ de óleo de soja e $75 \%$ óleo ácido de soja, OS50AC50: mistura de 50\% de óleo de soja e 50\% de óleo ácido de soja, OS50FR50: mistura de 50\% de óleo de soja e $50 \%$ de óleo de vísceras de aves.

\subsection{Valor de TBARS}

Os valores médios de TBARS das sobrecoxas variaram de 0,21 a 0,23, no início do experimento a 0,59 a $0,90 \mathrm{mg}$ de malonaldeído/ $\mathrm{kg}$ ao final dos 9 meses de experimento (Tabela 18), sendo o período de armazenamento um fator preponderante para esta diferença. A qualidade oxidativa da sobrecoxa de frango de todos os tratamentos manteve-se sob controlado processo de deterioração oxidativa até os seis meses de armazenamento, atingindo valores entre 0,32 e 0,41 $\mathrm{mg}$ de malonaldeído/kg, o que também foi observado por Jensen et al. (1998). Com 9 meses de congelamento, as sobrecoxas 
apresentaram um acúmulo generalizado de produtos secundários de ranço, atingindo 0,79 e $0,90 \mathrm{mg}$ de malonaldeído/kg nas amostras dos tratamentos OS50AC50 e OS50FR50, respectivamente. Racanicci (2004), que também trabalhou com sobrecoxas de frango, verificou o mesmo comportamento de aumento dos valores de TBARS no período inicial do armazenamento congelado. Seus valores variaram de 0,160 iniciais a 0,474 mg de malonaldeído/kg no quinto mês, e até $0,758 \mathrm{mg}$ de malonaldeído/kg no nono mês de armazenamento das sobrecoxas de frangos alimentados com dietas adicionadas de óleo de vísceras oxidado. Este aumento generalizado do nível oxidativo da carne durante o armazenamento congelado pode ter ocorrido devido a uma possível desidratação provocada pela baixa temperatura, que pode ter resultado em uma redução da atividade da água da carne. Sabe-se, através da literatura (Van Laack, 1994), que a redução da Aa na faixa de 0,8 a 0,6, pode favorecer a deterioração lipídica.

Além disso, a composição dos ácidos graxos existentes na carne também deve ter afetado negativamente a qualidade das sobrecoxas, visto que as carnes dos animais alimentados com dietas adicionadas das misturas OS50/FR50 e OS50/AC50 apresentaram a maior quantidade de ácidos graxos insaturados de todos os tratamentos. Isto fica ainda mais evidente, se for comparada a composição em ácidos graxos da carne do tratamento OS50/AC50 com a do tratamento AC, que apresentou os valores mais baixos de TBARS ao final do experimento, apesar da baixa qualidade inicial de do óleo ácido. 
Tabela 18. Valores médios de TBARS (mg de malonaldeído/kg da amostra) para carne de sobrecoxa de frango dos diferentes tratamentos $(n=3)$

\begin{tabular}{lcccccc}
\hline Fontes & \multicolumn{5}{c}{ Período de Armazenamento (Meses) } \\
Lipídicas & 0 & 1 & 2 & 4 & 6 & 9 \\
\hline OS & $0,23^{f}$ & $0,29^{\text {ef }}$ & $0,33^{\text {de }}$ & $0,39^{\text {bcd }}$ & $0,37^{\text {cdAB }}$ & $0,67^{\text {aCDE }}$ \\
FR & $0,21^{f}$ & $0,29^{\text {de }}$ & $0,28^{\mathrm{e}}$ & $0,36^{\text {bc }}$ & $0,32^{\text {cdeB }}$ & $0,63^{\text {aEF }}$ \\
AC & $0,23^{f}$ & $0,29^{\text {ef }}$ & $0,34^{\text {de }}$ & $0,39^{\text {bcd }}$ & $0,35^{\text {cdeAB }}$ & $0,59^{\text {aF }}$ \\
OS25AC75 & $0,23^{f}$ & $0,30^{\mathrm{e}}$ & $0,32^{\text {de }}$ & $0,35^{\text {cde }}$ & $0,36^{\text {bcdeAB }}$ & $0,64^{\text {aDEF }}$ \\
OS50AC50 & $0,22^{f}$ & $0,30^{\mathrm{e}}$ & $0,33^{\text {de }}$ & $0,41^{\text {bc }}$ & $0,39^{\text {cdA }}$ & $0,79^{\text {aB }}$ \\
OS50FR50 & $0,22^{f}$ & $0,34^{\mathrm{e}}$ & $0,34^{\text {de }}$ & $0,40^{\text {cde }}$ & $0,41^{\text {bcdeA }}$ & $0,90^{\text {aA }}$
\end{tabular}

a - letras minúsculas diferentes na mesma linha diferem estatisticamente entre si $(\mathrm{P}<0,05)$

A - letras maiúsculas diferentes na mesma coluna diferem estatisticamente entre si $(P<0,05)$

Coeficiente de Variação: 5,53\%

Legenda: OS: óleo de soja, FR: óleo de vísceras de aves, AC: óleo ácido de soja, OS25AC75: mistura de $25 \%$ de óleo de soja e $75 \%$ óleo ácido de soja, OS50AC50: mistura de 50\% de óleo de soja e 50\% de óleo ácido de soja, OS50FR50: mistura de 50\% de óleo de soja e 50\% de óleo de vísceras de aves.

\subsection{Análise Sensorial}

A análise sensorial realizada com provadores treinados mostrou que 0 odor de ranço se fez mais perceptível (nota maior) no decorrer do armazenamento da carne e também nas amostras de frangos alimentados com óleo de vísceras de aves e as misturas de óleo de soja com óleo ácido e óleo de soja com óleo de vísceras de frango (Tabela 19).

Foi percebida uma significativa diferença entre os tratamentos, principalmente entre as amostras acima citadas em relação às amostras de óleo de soja e óleo ácido de soja.

Ao final do experimento, o tratamento OS50FR50 apresentou valor de TBARS alto, cerca de 0,9 mg de malonaldeído por kilograma da amostra, valor que para alguns pesquisadores é considerado suficiente para a percepção de ranço no alimento, conforme ocorrido nesta avaliação.

Olivo e Shimokomaki (2001) afirmaram que produtos com índice de TBA 
menor que $1,0 \mathrm{mg} / \mathrm{kg}$ geralmente não acrescentam sabores e odores residuais de ranço característicos de oxidação lipídica, contudo Torres et al. (1994) ressaltaram que o valor de TBARS necessário para a percepção de ranço foi de 0,6 a 2,0 mg de malonaldeído por kilograma de amostra em carnes cozidas. Jensen et al. (1998) reportaram que 0,5 mg de malonaldeído/kg foi suficiente para a detecção de ranço em carne suína por provadores treinados.

Contrariando as expectativas as amostras de frango alimentados com óleo ácido foram tão bem aceitas, quanto as do tratamento óleo de soja.

Tabela 19. Notas médias (ou intensidade de odor de ranço) dos provadores para o atributo odor de ranço nas carnes de frango $(n=15)$

\begin{tabular}{lcccccc}
\hline Tratamentos & \multicolumn{5}{c}{ Período de Armazenamento (Meses) } \\
& 0 & 1 & 2 & 4 & 6 & 9 \\
\hline OS & $0,54^{\mathrm{fDE}}$ & $0,66^{\mathrm{efC}}$ & $0,70^{\mathrm{defE}}$ & $4,24^{\mathrm{CE}}$ & $4,57^{\mathrm{bCD}}$ & $6,87^{\mathrm{aC}}$ \\
FR & $3,90^{\mathrm{fBC}}$ & $5,25^{\mathrm{eA}}$ & $6,31^{\mathrm{dA}}$ & $7,10^{\mathrm{cdB}}$ & $7,87^{\mathrm{bcA}}$ & $8,90^{\mathrm{aA}}$ \\
AC & $0,53^{\mathrm{fE}}$ & $0,83^{\mathrm{eBC}}$ & $0,93^{\mathrm{dDE}}$ & $4,40^{\mathrm{cDE}}$ & $4,88^{\mathrm{bcCD}}$ & $6,98^{\mathrm{aBC}}$ \\
OS25AC75 & $4,50^{\mathrm{dABC}}$ & $4,56^{\mathrm{cdA}}$ & $4,78^{\mathrm{bcdBC}}$ & $8,16^{\mathrm{aA}}$ & $8,28^{\mathrm{aA}}$ & $8,92^{\mathrm{aA}}$ \\
OS50AC50 & $5,20^{\mathrm{dA}}$ & $5,36^{\mathrm{cdA}}$ & $5,73^{\mathrm{bcdA}}$ & $8,54^{\mathrm{aA}}$ & $8,58^{\mathrm{aA}}$ & $8,75^{\mathrm{aA}}$ \\
OS50FR50 & $3,90^{\mathrm{fC}}$ & $5,24^{\mathrm{dA}}$ & $4,18^{\mathrm{efC}}$ & $6,52^{\mathrm{cA}}$ & $6,80^{\mathrm{bcB}}$ & $8,75^{\mathrm{aA}}$
\end{tabular}

a - letras minúsculas diferentes na mesma linha diferem estatisticamente entre si $(P<0,05)$

A - letras maiúsculas diferentes na mesma coluna diferem estatisticamente entre si $(P<0,05)$

Coeficiente de variação Tempo 0: 44,57\%, Tempo 1: 22,25\%, Tempo 2: 16,18\%, Tempo 4: 8,18\%, Tempo 6: 9,32\%, Tempo 9: 13,30\%.

Legenda: OS: óleo de soja, FR: óleo de vísceras de aves, AC: óleo ácido de soja, OS25AC75: mistura de $25 \%$ de óleo de soja e 75\% óleo ácido de soja, OS50AC50: mistura de 50\% de óleo de soja e 50\% de óleo ácido de soja, OS50FR50: mistura de 50\% de óleo de soja e 50\% de óleo de vísceras de aves. 


\section{CONCLUSÕES}

Dentro das condições experimentais, concluiu-se que a fonte lipídica da dieta exerce influência preponderante sobre a qualidade oxidativa da carne de de frangos e que o armazenamento sob congelamento intensificou as reações do processo oxidativo da fração lipídica das sobrecoxas, principalmente nas amostras de carnes de animais que foram alimentados com dietas cujas gorduras apresentaram baixa qualidade oxidativa.

Neste experimento a dieta contendo $50 \%$ óleo de soja e $50 \%$ óleo de vísceras foi a que mais afetou a qualidade e a estabilidade oxidativa da carne armazenada sob congelamento e os prejuízos causados pela oxidação lipídica foram verificados através do valor de TBARS e comprovados pela análise sensorial com provadores treinados.

O óleo ácido de soja foi a fonte lipídica adicionada às dietas de pior qualidade. Contudo, contrariando as expectativas, as sobrecoxas de frangos desse tratamento não apresentaram qualidade e estabilidade oxidativa baixa se comparadas às amostras dos outros tratamentos, comprovada pelos valores de TBARS inferiores aos dos outros tratamentos, bem como menor intensidade de odor de ranço detectado durante a análise sensorial.

A análise do perfil de ácidos graxos das sobrecoxas de frangos não apresentou uma diferença significativa na sua composição entre os tratamentos, apenas as amostras da carne dos animais alimentados com dieta adicionada de óleo ácido de soja apresentaram uma redução na porcentagem de ácidos graxos linoléico e linolênico.

O tempo de armazenamento não influiu no perfil de ácidos graxos das 
amostras.

Tempos de armazenamento de até seis meses sob congelamento parecem garantir a qualidade oxidativa e organolética de carnes de sobrecoxas de frangos para consumo. 


\section{REFERÊNCIAS BIBLIOGRÁFICAS}

ADAMS, C. A. Nutricines: food components in health and nutrition. Nottingham: Nottingham University Press, 1999. cap.2, p.11-32: Oxidation and antioxidants.

ALLEN, C. E.; FOEGEDIND, E. A. Some lipid characteristics and interactions in muscle foods. A review. Food Technology, v.35, p.253-257, 1981.

AMERICAN OIL CHEMISTS' SOCIETY. Official methods and recommended practices. 5. ed. Champaign: AOCS, 1997. 2v.

ARDITO, E. F. G., ALVES, R. M. V. Embalagens para alimentos congelados. Coletânea do Instituto Tecnologico de Alimentos, v. 24, n. 1, p. 11-28, 1994.

ASGHAR, A.; LIN, C. F.; CRAY, J. I.; BUCKLEY, D. J.; BOOREN, A. M.; FLEGAL, C. J. Effect of dietary oils and $\propto$-tocopherol supplementation on membranal lipid oxidation in broiler meat. Journal Food Science, v.55, p.4650, 1990.

ASSOCIATION OF OFFICIAL ANALYTICAL CHEMISTS. Official methods of analysis. 15. ed. Washington: AOAC, 1995. 2v. 
BERAQUET, N. J. Carne mecanicamente separada de aves. Campinas: ITAL, 2000. 92p.

BLIGH, E. G.; DYER, W. J. A rapid method of total lipid extraction and purification. Canadian Journal of Biochemistry and Physiology, v.37, n.8, p.911-917, Aug. 1959.

BOU, R.; GUARDIOLA, F.; GRAU, A.; GRIMPA, S.; MANICH, A.; BARROETA, A.; CODONY, R. Influence of dietary fat source, $\alpha$-tocopherol, and ascorbic acid supplementation on sensory quality of dark chicken meat. Poultry Science, v.80, p.800-807, 2001.

BRUE, R. N.; LATSHAW, J. D. Energy utilization by the chicken as affected by various fats and fat levels. Poultry Science, v.64, p.2119-2130, 1985.

CAMBERO, M. I.; DE LA HOZ, L.; SANZ, B.; ORDÓNEZ, J. A. Lipid and fatty acid composition of rabbit meat: part 1- Apolar fraction. Meat Science, v.29, p.153-166, 1991a.

CAMBERO, M. I.; DE LA HOZ, L.; SANZ, B.; ORDÓNEZ, J. A. Lipid and fatty acid composition of rabbit meat: part 2- Polar fraction. Meat Science, v.29, p.167-176, 1991 b.

CHRISTIE, W.W. Lipid analysis. Oxford: Pergamon Press, 1982. cap.3, p.2549: Chromatografic and spectroscopic analysis of lipids. General principles.

COBOS, A.; DE LA HOZ., L.; CAMBERO, M. I.; ORDÓNEZ, J. A. Revisión: Influencia de la dieta animal en los ácidos grasos de los lípidos de la carne. Revista Espanõla de Ciencia y Tecnología de Alimentos, v.34, n.1, p.3551, 1994. 
COMBS, G. F. The vitamins. London: Academic Press, 1998. cap.7, p.189-222: Vitamin E.

DUTICOSKY, S. D. Análise sensorial de alimentos. Curitiba: Champagnat, 1996. 123p.

ERICKSON, D. R. Practical handbook of soybean processing and utilization. Champaign: AOCS Press, 1995. 582p.

ESTADOS UNIDOS. Departament of Agriculture. Agricultural Research Service. 2004. USDA National nutrient database for standard reference, release 16-1. Nutrient data laboratory home page. http://www.nal. usda.gov/fnic/foodcomp/ (10 Nov. 2004).

FARMER, E. H.; BLOOMFIELD, G. F.; SUNDARALINGAM, A.; SUTTON, D. A. The course and mechanism of autoxidation reactions in olefinic and polyolifinic substances, including rubber. Transactions of the Faraday Society, v.38, p.348-356, 1942.

FRANCO, G. Tabela de composição química dos alimentos. 9.ed. São Paulo: Atheneu, 2001. 356p.

GAIOTTO, J. B. Determinação da energia metabolizável de gorduras e sua aplicação na formulação de dietas para frangos de corte. Piracicaba, 2004. 92p. Tese (Doutorado) - Escola Superior de Agricultura "Luiz de Queiroz", Universidade de São Paulo.

GENOT, C. Congelación y calidad de la carne. Zaragoza: Acribia, 2000. $104 p$. 
GERMAN, J. B. Muscle lipids. Journal Muscle Foods, v.1, p.339-361, 1990.

GRAU, A.; GUARDIOLA, F.; GRIMPA, S.; BARROETA, A. C.; CODONY, R. Oxidative Stability of dark chicken meat through frozen storage: influence of dietary fat and $\alpha$-tocopherol and ascorbic acid supplementation. Poultry Science, v.80, p.1630-1642, 2001.

GRAY, J. I.; GOMAA, E. A.; BUCKELEY, D. J. Oxidative quality and shelf life of meats. Meat Science, v.43, p.111-123, 1996.

HARTMAN, L.; LAGO, R. C. Rapid determination of fatty acid methyl esthers from lipids. Laboratory Practice, v.22, n.7, p.475-476, 1973.

INTERNATIONAL UNION OF PURE AND APPLIED CHEMISTRY. Standard methods for analyses of oils, fat and derivates. 6 ed. Oxford: Pergamon Press, 1979. 2v.

JENSEN, C.; ENGBERG, R.; JAKOBSEN, K.; SKIBSTED, L. H.; BERTELSEN, G. Influence of the oxidative quality of dietary oil on broiler meat storage stability. Meat Science, v. 47, n.3/4, p.211-222, 1998.

KAREL, M. Physical principles of food preservation. Madison: CRC Press, 1975, cap. 10, p. 309-358: Dehydration of foods.

KETELS, E.; DE GROOTE, G. Effect of ratio of unsaturated to saturated fatty acids of dietary lipid fraction on utilization and metabolizable energy of added fats in young chickens. Poultry Science, v.68, p.1506-1512, 1989. 
KONDAIAH, N.; PANDA, B. Effect of hot and cold boning of spent hens on carcass components and functional properties of frozen meat. International Journal of Food Science and Technology, v.22, p.413-416, 1987.

KROGDAHL, A. Digestion and absorption of lipid in poultry. Journal of Nutrition, v.15, p.675-685, 1985.

LABUZA, T. P. Shelf-life dating foods. Chicago: Food \& Nutrition Press, 1982. cap. 10. p. 359-372: Basic food preservation and degradation modes.

LIN, K. Soybeans: chemistry, technology and utilization. New York: Chapman and Hall, 1999. 532p.

MAFFI, G. L. Graxarias e subprodutos. In: CONFERÊNCIA APINCO DE CIÊNCIA E TECNOLOGIAS AVÍCOLAS. Campinas, 1993. Anais. Campinas: FACTA, 1993, p.191-201.

MAYNARD, L. A.; LOOSLI, J. K.; HINTZ, H. F.; WARNER, R. G. Nutrição animal. 3.ed. Rio de Janeiro: Livraria Freitas Bastos, 1984. cap. 7, p.121159: Os lipídios e seu metabolismo.

MIELCHE, M. M.; BERTELSEN, G. Approaches to the prevention of warmedover flavour. Trends in Food Science and Tecnology, v.5, p.322-327, 1994.

MORGAN, C. A.; NOBLE, R.C.; COCCHI, M.; MCCARTNEY, R.; Manipulation of the fatty acid composition of pig meat lipids by dietary means. Journal Science Food Agriculture, v.58. p.357-368, 1992. 
MORRISSEY, P. A.; SHEEHY, P. J.; GALVIN, K.; KERRY, J. P.; BUCKLEY, D. J. Lipid stability in meat and meat products. Meat Science, v.49, n.1, p.73-86, 1998.

NETO, G. J. Abate e processamento de frangos. Campinas: FACTA, 1994. $150 p$.

OLÍVIO, R.; SHIMOKOMAKI, M. Carnes no caminho da pesquisa. Cocal do Sul: Imprint, 2001. 155p.

PAINE, F. A.; PAINE, H. Y. A handbook of food packing. Glasgow: Blackie Academic \& Professional, 1983. 497p.

QIAO, M.; FLECHER, D. L.; SMITH, D. P.; NORTHCUTT, J. K. The effect of broiler breast meat color on $\mathrm{pH}$, moisture, water-holding capacity and emulsification capacity. Poultry Science,v.80, n.5, p.676-680, 2001.

QIAO, M.; FLECHER, D. L.; SMITH, D. P.; NORTHCUTT, J. K. The relationship between raw broiler breast meat color and composition. Poultry Science, v.81, n.3, p.422-427, 2002.

RACANICCI, A. M. C. O efeito do uso do óleo de vísceras de aves oxidado no desempenho de frangos de corte e na estabilidade oxidativa da carne da sobrecoxa. Piracicaba, 2004. 80p. Tese (Doutorado). Escola Superior de Agricultura "Luiz de Queiroz", Universidade de São Paulo.

RENNER, R.; HILL, F. W. Factors affecting the absorbability of struturated fatty acids in the chick. Journal of Nutrition, v.74, p.254-258, 1961. 
RHEE, K. S.; ZIPRIN, Y. A.; ORDONEZ, G.; BOHAC, C. E. Fatty acid profiles and lipid oxidation in pork muscles as affected by canola oil in the animal diet and muscle location. Meat Science, v.23, p.201-210, 1988.

ROBERTSON, G. L. Food packaging: principles and practice. New York: Marcel Decker, 1992. 676p.

ROSTAGNO, H. S. Tabelas brasileiras para aves e suínos: composição de alimentos e exigências nutricionais. Viçosa: Universidade Federal de Viçosa, Departamento de Zootecnia, 2000. 141p.

SARANTÓPOULOS, C. I. G. L.; OLIVEIRA, L. M.; ANJOS, V. D. A.; ALVES, R. M. V.; ARDITO, E. F. G. Embalagem para produtos cárneos. Campinas: CETEA/ITAL, 1991. 92p.

SARANTÓPOULOS, C. I. G. L.; OLIVEIRA, L. M.; CANAVESI, E. Requisitos de conservação de alimentos em embalagens flexíveis. Campinas: CETEA/ITAL, 2001. 213p.

SARANTÓPOULOS, C. I. G. L.; OLIVEIRA, L. M.; PADULA, M.; COLTRO, L.; ALVES, R. M. V.; GARCIA, E. E. C. Embalagens plásticas flexíveis: principais polímeros e avaliação de propriedades. Campinas: CETEA/ITAL, 2002. $267 p$.

SAS INSTITUTE. SAS: user's guide. version 6.11. 4. ed. Cary: SAS Institute, 1996. $956 \mathrm{p}$.

SCOTT, M. L.; NESHEIM, M. C.; YOUNG, R.J. Nutrition of the chicken. 3. ed. Ithaca: M. L. Scott \& Associates, 1982. 562p. 
SMEDES, F.; THOMASEN, T. K. Evaluation of the Bligh and Dyer lipid determination method. Marine Pollution Bulletin, v.32, n.8/9, p. 681-688, 1996.

STAZIONE SPERIMENTALE PER LE INDUSTRIE DEGLI OLI E DEI GRASSI. Norme italiane per il controllo dei grassi e derivate. 3 ed. Milano: Stazione Sperimentale per le Industrie degli Oli e dei Grassi, 1976.

STONE, H.J.; SIDÉL, S.; OLIVER, A.; WOOLSEY, R.C. Sensory evaluation by quantitative descriptive analysis. Food Technology, v.28, n.11, p.24-34, 1974.

TABELA BRASILEIRA DE COMPOSIÇÃO DE ALIMENTOS. http://www.fcf.usp.br/tabela (04/nov.2004).

TARLADGIS, B. G.; WATTS, B. M.; YOUNATHAN, M. T. A distillation method for the quantitative determination of malonaldehyde in rancid foods. Journal American Oil Chemist's Society, v.37, n.1, p.44-48, 1960.

TORRES, E. A. F. S.; PEARSON, A. M.; GRAY, J. I.; KU, P. K.;SHIMOKOMAKI, M. Lipid oxidation in charqui (salted and dried beef). Food Chemistry, v.32, p.257-268, 1989.

VAN LAACK, R. L. J. M. Spoilage and preservation of muscle foods. In: KINSMAN, D. M.; KOTULA, A. W.; BREIDENSTEIN, B. C. Muscle foods. New York: Chapman and Hall, 1994. cap.14, p.378-405.

WALDROUP, P. W.; WALKINS, S. E.; SALEH, E. A. Comparison of two blended animal - vegetable fats having low or high free fatty acid content. Journal of Applied Poultry Research, v.4, p.41-48, 1995. 
YOUNG, R. J. The energy value of fats and fatty acids for chickens. 1. Metabolizable energy. Poultry Science, v.40, p.1225-1239, 1961.

ZOLLITSCH, W.; KNAUS, W.; ALCHINGER, F. Effects of different dietary and carcass characteristics of broiler. Animal Feed Science and Technology, v.66, p.63-73, 1997. 